\title{
Crystalloid versus Colloid in Stabilizing Hemodynamic of Patients Undergoing Cesarean Section with Neuraxial Anesthesia A Randomized Controlled Trial
}

Shiqin Xu, M.D., M.P.H.* Qingsong Zhao, M.D.* Fuzhou Wang, M.D., Ph.D.* Haibo Wu, M.Sc.* Wei Wang, M.D., M.Sc. Dongying Fu, B.Nr. Yusheng Liu, M.D., M.Sc. Xian Wang, M.D., Ph.D. Fan Xia, M.D. Shanwu Feng, M.D., Ph.D. Xiaofeng Shen, M.D., M.P.H.

\section{SUMMARY}

Background: Neuraxial anesthesia-associated maternal hypotension in cesarean delivery is the most frequent and troublesome complication poses serious risks to mother and compromises neonatal well-being. The use of intravenous fluid loading as the preventive strategy in this context has been challenged because inconsistent results cause doubt on its real efficacy. We compared hypotensionpreventing effect of crystalloid and colloid with different loading regimens given in a volume-escalation manner in neuraxial anesthetized cesarean parturients. Methods: One thousand parturients with American Society of Anesthesiologists (ASA) physical status I/II undergoing selective cesarean delivery were screened and 939 were assigned into different fluid loading regimens with a multi-stage randomization. The volume of crystalloid or colloid in each loading regimen was determined by an up-and-down sequential method. Rate of hypotension was recorded as the primary outcome, and the median (EV50) and $90 \%$ effective volumes (EV90) of fluids were calculated in epidural and spinal blockades.

Results: A total of 469 subjects were analyzed in the crystalloid group and 470 in the colloid group. The numbers of patients developed clinically significant and severe hypotension are significantly decreased, and the effective volume of colloid required in preventing hypotension in both anesthetized populations is relatively lower than that of crystalloid on the intention-to-treat analyses. There is still an occurrence of hypotension at a rate of about $10 \%-20 \%$ even when the EV90 was reached.

Conclusions: Fluid loading is an effective maneuver in balancing maternal circulation when reaching the effective volume of different neuraxial anesthesia, but prophylactic or therapeutic vasoconstrictors should also be prepared and be given at an appropriate time because a significant proportion of women can still develop hypotension.

KEYWORDS C-Section; Fluid; Neuraxial Anesthesia; Hemodynamic; Outcomes
Clinical Trial Registration: This trial is registered with ClinicalTrials.gov identifier: NCT01013090.

Sci Insigt. 2019; 2019:e0012. doi:10.15354/si.19.ar009 
HE rate of Cesarean delivery remains an upward trend worldwide, especially among women in low-resource countries. Approximately one third labor deliveries are performed by using cesarean section every year, of which takes over $80 \%$ of all the cases that are done under the neuraxial anesthesia $(1,2)$. Neuraxial anesthesia-associated maternal hypotension is the major circulation-unbalancing factor, and also the most frequent and troublesome complication resulted from sympathetic blockade, of which poses serious risks to mother, such as unconsciousness, pulmonary aspiration, hepatic dysfunction, apnea or even cardiac arrest, and compromises neonatal well-being, such as impaired uteroplacental blood perfusion leading to hypoxia, significant fetal acidosis and neurological injury (3-6). Prophylaxis, thereby, has been being a decades-long issue debated, but the optimal maneuver for preventing such an incidence is still not acquired.

Multiple strategies are currently used to guard against the occurrence of hypotension during regional anesthesia for elective or emergency cesarean delivery, but no definitive consensus has been reached on the best treatment strategy. Physical interventions, for instance, a left-lateral tilt position proceeded to increase the venous return blood volume through displacing gravid uterus off the inferior vena cava (7) and lower limb compression carried out by wrapping legs to minimize venous pooling blood (8), can produce unintentional effects on mothers such as unacceptable discomfort, localized ischemia or nerve injury. Pharmaceutical therapies including ephedrine, phenylephrine, metaraminol and mephentermine are prescribed to constrict the peripheral circulation and increase cardiac output $(9,10)$, however, they have potential dangers to evoke maternal supraventricular dysrhythmia, tachyphylaxis, anaphylaxis and hypertension, and also increase the risk of fetal acidosis for impaired uteroplacental flow secondary to vasoconstriction. Intravenous fluid management is now accepted as a standard means in preventing neuraxial block-induced hypotension, though, the choice of fluid type (crystalloid or colloid) (11-15), intervention timing (pre-, co- or postanesthesia loading) (16-19), titrating speed (pressuredfast, fast or slow) $(20,21)$ and volumes given (high or low) $(22,23)$ are still the debated topics and different choices have yielded different results.

Clinical guidelines recommend that intravenous fluid preloading should be used to reduce the risk of maternal hypotension after neuraxial anesthesia for cesare- an delivery, but no detailed strategies were given concerning how to realize this purpose $(24,25)$. A recent Cochrane systematic review showed an effectiveness sequence of fluids in reducing the frequency of hypotension underwent spinal anesthesia: colloids > crystalloids > no fluids, but no differences were found for different doses, rates or methods of administering colloids or crystalloids (26), in which the included studies did not do any calculating investigation on the minimal effective volume of fluids under spinal block. Pre-loading the circulation is aimed at the volume expansion that alleviates the vasodilation induced by regional anesthesia, nonetheless, co-loading or post-loading regimen has been proposed due to a much more effective role in decreasing the rate of hypotension (16-19). In addition, given the fact of a significantly increased blood volume in parturients plus a relatively reduced effective circulation volume after neuraxial anesthesia, conventional methods of fluid management, either 'liberal' (2,000 $\mathrm{ml} /$ person) or 'restricted' (500 ml/person), all did not produce ideal effects on preventing hypotension and ameliorating circulation balance.

In January 2009, we initiated a randomized controlled trial to assess the effectiveness of crystalloid and colloid in balancing circulation by preventing hypotension in cesarean parturients at different fluid loading regimens under epidural or spinal anesthesia and calculate the effective volumes of fluids through an up-down volume-escalation method.

\section{METHODS}

\section{Participants and Ethics}

Ethical approval obtained from the Institutional Ethics Examining Committee of Human Research before recruiting patients. All participants signed an informed consent and a full explanation was given to those willing to accept neuraxial anesthesia (epidural or spinal block) with respect to epidural puncture and catheterization, lumbar spinal puncture, the opioid and local anesthetics used in this study, and possible risks and complications might appear during study. Recruitment for the trial took place between January 2009 and March 2011. Screened-for-participating parturients were eligible if they were undergoing elective cesarean delivery, were ages between 19 and $40 \mathrm{yr}$, and fulfilled the following criteria: gestational age $>=36 \mathrm{wk}$, American So- 


\section{Figure 1. Trial Profiles of Enrollment, Screening, and Randomization.}

\section{Assessed for eligibility $(\mathrm{n}=1,000)$}

Excluded for other reasons $(\mathrm{n}=21)$

With pregnancy-induced hypertension $(\mathrm{n}=8)$

With gestational diabetes $(n=6)$

Had coagulation dysfunction $(n=3)$

Unsuitable for epidural or spinal puncture* $(n=3)$

With HELLP syndrome $\dagger(n=1)$

Not meeting inclusion criteria $(\mathrm{n}=26)$

Age $>40$ yr $(\mathrm{n}=9)$

Height $<140 \mathrm{~cm}$ or $>175 \mathrm{~cm}(\mathrm{n}=7)$

Gestational age $<36 \mathrm{wk}(\mathrm{n}=6)$

Twin pregnancy $(\mathrm{n}=4)$

Declined to participate $(\mathrm{n}=14)$

\section{Underwent randomization $(\mathrm{n}=939)$}

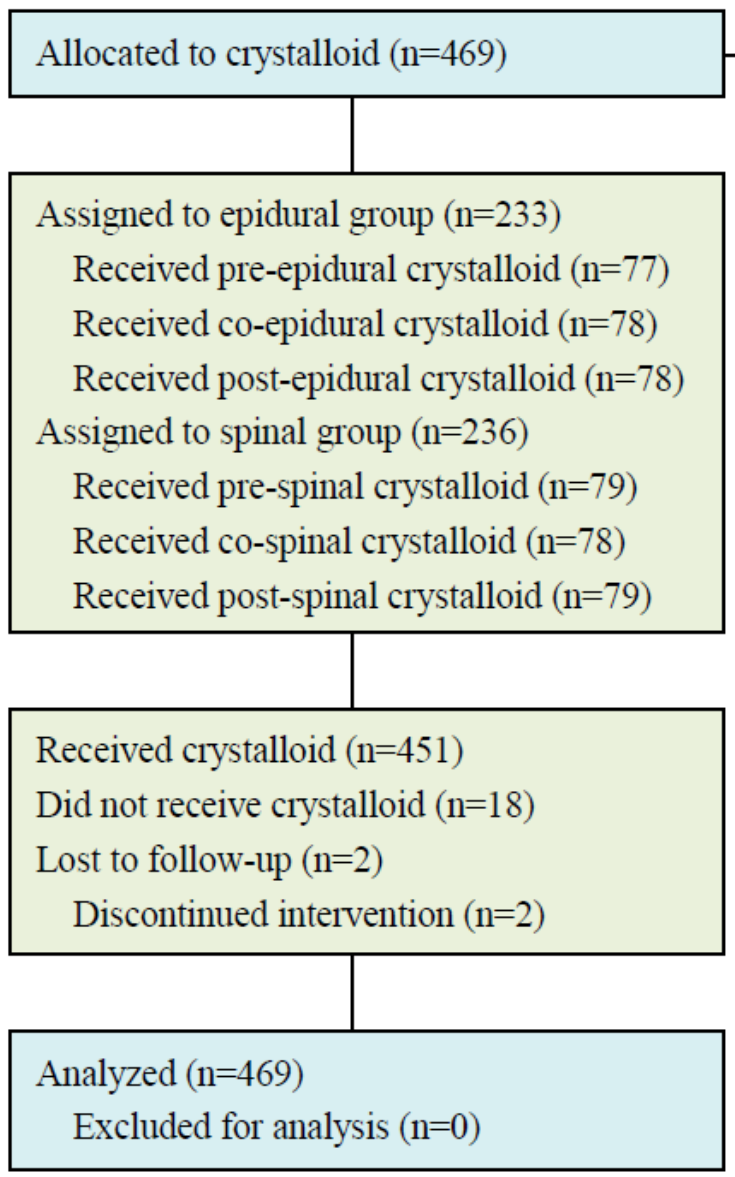

Allocated to colloid $(\mathrm{n}=470)$

Assigned to epidural group ( $\mathrm{n}=237$ )

Received pre-epidural colloid $(\mathrm{n}=79)$

Received co-epidural colloid ( $\mathrm{n}=79)$

Received post-epidural colloid ( $\mathrm{n}=79)$

Assigned to spinal group ( $\mathrm{n}=233$ )

Received pre-spinal colloid $(\mathrm{n}=76)$

Received co-spinal colloid $(\mathrm{n}=79)$

Received post-spinal colloid ( $\mathrm{n}=78)$

\begin{tabular}{|l|}
\hline Received colloid ( $\mathrm{n}=455)$ \\
$\begin{array}{l}\text { Did not receive colloid }(\mathrm{n}=15) \\
\text { Lost to follow-up }(\mathrm{n}=5) \\
\text { Discontinued intervention }(\mathrm{n}=5)\end{array}$ \\
\hline $\begin{array}{l}\text { Analyzed }(\mathrm{n}=470) \\
\text { Excluded for analysis }(\mathrm{n}=0)\end{array}$ \\
\hline
\end{tabular}

* Detailed reasons for those unsuitable for performing epidural or spinal puncture were displayed in the text † HELLP syndrome refers to hemolysis, elevated liver enzyme and low platelets syndrome 
ciety of Anesthesiologists (ASA) physical status I to II, uncomplicated singleton pregnancy.

\section{Randomization}

When patients entered operating room, a further assessment based on the overall previously-initiated evaluation was done. After confirmation of the signed anesthetic information, a multi-stage randomization was carried out (flow of the patient allocation see Supplementary Materials Figure S-1). First of all, the patients were randomized into either crystalloid or colloid intervention, of which followed by a second-stage random allocation into epidural or spinal anesthesia, respectively. Subsequently, the third-stage randomization was performed to assign subjects to pre- (20 min prior to anesthesia induction), co- (simultaneous administration with anesthesia performance) or post-anesthesia (immediately given after completion of anesthetic injection) fluid loading subgroup. The random number lists of the three stages were generated by means of the QuickCalcs (Online Calculators for Scientists, available at http:/www.graphpad.com/quickcalcs/RandMenu.cfm; last accessed March 29, 2016. GraphPad Software Inc., La Jolla, San Diego, CA). Finally, the last-stage randomized patient received crystalloid or colloid with different doses determined by following an up-and-down sequential method (number of patients assigned to each subgroup is listed in Supplementary Materials Table S-1) (27). The healthcare providers, data-collecting members, and parturients were not masked to the group allocation except for data-analyzing members and outcome adjudicators.

\section{Demographic Characteristics}

The following data were collected as demographic characteristics of the subjects: age at delivery, weight, height, gestational age of fetus, current status of smoking, nulliparous or multiparous status and maternal vital signs (blood pressure, heart rate, respiratory rate and oral temperature).

\section{Exclusion Criteria}

Parturients were excluded from the study if one or more of the following criteria were met: (i) allergy to local anesthetics or opioids; (ii) a history of psychiatric diseases records; (iii) participants younger than $18 \mathrm{yr}$ or older than $40 \mathrm{yr}$; (iv) those who were not willing to or could not finish the whole study; (v) primary hypertension, gestation-induced hypertension or preeclampsia; (vi) diagnosed diabetes mellitus or gestation-associated diabetes mellitus; (vii) subjects with a nonvertex presentation or scheduled induction of labor; (viii) emergency cesarean section or parturients failed vaginal delivery with neuraxial analgesia; (ix) twin gestation and breech presentation; ( $\mathrm{x}$ ) contraindications for performing neuraxial anesthesia (detailed list of the contents see Supplementary Materials Table S-2).

\section{Study Procedures}

After completion of the randomization, patients were given the initial volume of fluids: crystalloid $(5 \mathrm{ml} / \mathrm{kg}$ of Lactated Ringer's solution) and colloid (4 ml/kg of hydroxyethyl (HES) 130/0.4 (Voluven ${ }^{\circledR}$ 6\%, Fresenius Kabi, Bad Homburg, Germany). These volumes were chosen based on our clinical experience and statistical simulation at various doses from previous observation (Data are not shown). Each subsequent volume was relying on the response of the preceding subject via following Dixon's biased-coin design up-and-down sequential method (27). The changing volumes of both fluids were in an increment of $1 \mathrm{ml} / \mathrm{kg}$. The anesthesia provider was blinded to the volume of the given fluids, as was the parturient. If a given volume, in our study, encountered a failure in preventing hypotension, the following subject would be given the same volume of the fluids again, and the volume would not be stepped up in the next subject until the third patient still failed to response to the same volume. All response-failed women were prescribed a repeatable ephedrine 6-10 mg intravenously. If a successful prevention was observed, the next parturient was randomly assigned to the next lower volume with a probability of 0.1 and to the same volume with a probability of 0.9 as described elsewhere (28). The infusion of all fluids must be completed within 15 min whenever pre-, co- or post-anesthesia. Ringer's lactate solution at a titrating rate of $10 \mathrm{ml} / \mathrm{min}$ was followed after completion of all interventional fluid regimens and the total volume was calculated at the end of the study.

In the epidural anesthesia section, all parturients received extradural puncture and catheterization between L2 and L3 in the left-lateral position. The test dose of $3.0 \mathrm{ml}$ of lidocaine $1.5 \%$ (45 mg) plus $5 \mu \mathrm{g} / \mathrm{ml}$ epinephrine was given. After delivering a test dose, all 


\section{Table 1. Baseline Characteristics of Subjects.*}

\begin{tabular}{lcccc}
\multicolumn{1}{c}{ Characteristic } & \multicolumn{2}{c}{ Crystalloid } & \multicolumn{2}{c}{ Colloid } \\
\cline { 2 - 5 } & $\begin{array}{c}\text { Epidural } \\
(\mathbf{n = 2 3 3 )}\end{array}$ & $\begin{array}{c}\text { Spinal } \\
(\mathbf{n = 2 3 6 )}\end{array}$ & $\begin{array}{c}\text { Epidural } \\
(\mathbf{n = 2 3 7 )}\end{array}$ & $\begin{array}{c}\text { Spinal } \\
(\mathbf{n = 2 3 6})\end{array}$ \\
\hline Age at delivery, $\mathrm{yr}$ & $26 \pm 8$ & $27 \pm 7$ & $28 \pm 9$ & $25 \pm 6$ \\
Weight, kg & $60 \pm 11$ & $58 \pm 12$ & $59 \pm 13$ & $61 \pm 14$ \\
Height, $\mathrm{cm}$ & $161 \pm 12$ & $158 \pm 7$ & $159 \pm 10$ & $162 \pm 11$ \\
Nullipara/Multipara, $\mathrm{n}$ & $223 / 10$ & $224 / 12$ & $220 / 17$ & $227 / 9$ \\
Gestational age, wk & $38(37-40)$ & $39(37-40)$ & $37(36-40)$ & $39(37-40)$ \\
Current smoker & $12(5.2)$ & $9(3.8)$ & $10(4.2)$ & $14(5.9)$ \\
Blood pressure, mmHg & & & & $119 \pm 16$ \\
Systolic pressure & $117 \pm 15$ & $108 \pm 11$ & $121 \pm 19$ & $67 \pm 8$ \\
\hline Diastolic pressure & $70 \pm 8$ & $68 \pm 6$ & $65 \pm 6$ & $78 \pm 12$ \\
Heart rate, bpm & $77 \pm 12$ & $73 \pm 10$ & $75 \pm 11$ & $19 \pm 4$ \\
Respiratory rate, bpm & $17 \pm 3$ & $19 \pm 4$ & $19 \pm 3$ & $36.8 \pm 0.5$ \\
\hline Oral temperature, ${ }^{\circ} \mathrm{C}$ & $37.1 \pm 0.3$ & $36.9 \pm 0.4$ & $37.0 \pm 0.3$ & 0.3 \\
\hline
\end{tabular}

* Data are presented as the means \pm standard deviation (SD), media (interquartile range) or number (\%), unless otherwise indicated.

$\mathrm{bmp}=$ beats per minutes of heart rate and breaths per minutes of respiratory rate.

participants received a $12-15 \mathrm{ml}$ epidural analgesic mixture in a single bolus of $0.75 \%(7.5 \mathrm{mg} / \mathrm{ml})$ ropivacaine with $10 \mu \mathrm{g} / \mathrm{ml}$ preservative-free morphine. In the spinal anesthesia section, all women received spinal anesthetic administered between L3 and L4 in the left-lateral position using hyperbaric $0.5 \%$ bupivacaine $2 \mathrm{ml}(10 \mathrm{mg})$ plus morphine $50 \mu \mathrm{g}$. After completion of the anesthetic procedures, patients were immediately repositioned supine with a $15^{\circ}$ left lateral tilt. The highest sensory block was checked and confirmed at the level of T6-T7 determined with loss-to-pinprick method bilaterally. Motor block was measured with modified Bromage scale ( 0 , no block; 1 , inability to raise extended leg; 2 , inability to flex knee; 3 , inability to flex ankle and foot).

After the anesthetic procedures were completed, arterial blood pressure was measured every minute for $10 \mathrm{~min}$ and then every $3 \mathrm{~min}$ for the duration of the study. In our study, hypotension was defined as systolic blood pressure (SBP) $<20 \%$ of baseline or SBP $<90$ $\mathrm{mmHg}$. Baseline arterial blood pressure was determined by measuring three time of the patient every $2 \mathrm{~min}$ at supine position with left uterine displacement.

\section{Peripartum Management and Monitoring}

A catheter was inserted in a right or left antecubital vein for fluid and drug administration. The maternal parameters monitored during the whole study included the heart rate by three-lead electrocardiograph, respiratory rate, noninvasive systolic and diastolic blood pressure, mean arterial pressure, oral temperature and fingertip pulse oximetry. The incidence of the maternal adverse events, such as nausea, vomiting, pruritus, shivering, fatigue, hemorrhage, headache, somnolence, hallucination, sweating, hypothermia, and pulmonary edema throughout the study were recorded. Metoclopramide $10 \mathrm{mg}$ can be administered intravenously if nausea or vomiting was unrelated to hypotension.

The following time intervals were recorded: titrating time of fluids (overall time of target fluids infused), induction of neuraxial anesthesia (from puncture positioning to successful injection of testing dose in epidural or anesthetic mixture in spinal), anesthetic induction to skin incision (from completion of anesthetic mixture injection to beginning of skin incision), uterine incision to delivery (from the start of uterine incision to umbilical-cord broken after baby delivered), duration of anesthesia (from completion of anesthetic mixture injection to sensory block disappeared) and surgery (from skin incision to the last skin suture). After delivery of the baby, 20 IU of oxytocin was titrated following Ringer's lactate solution.

\section{Fetal and Neonatal Management}




\section{Figure 2. Volume-Effect Relationship.}

A.

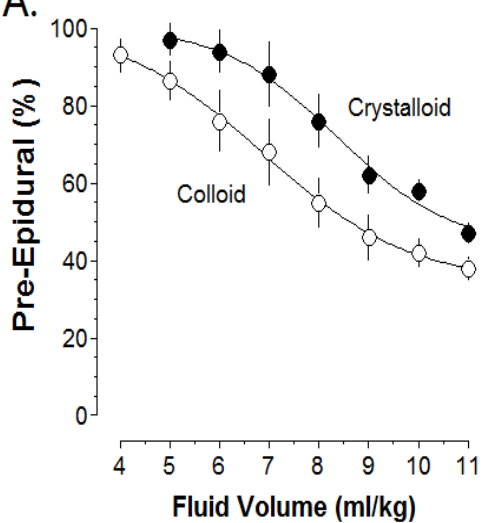

D.

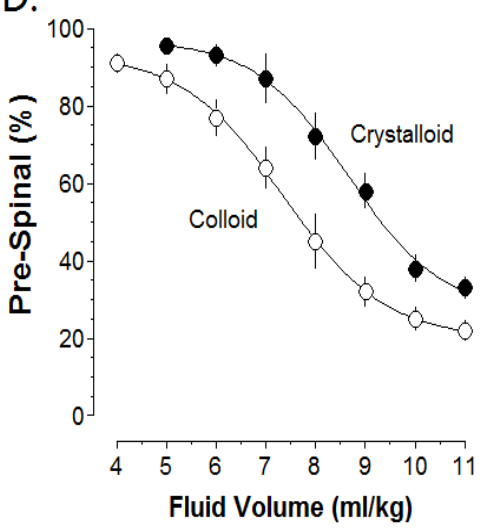

B.

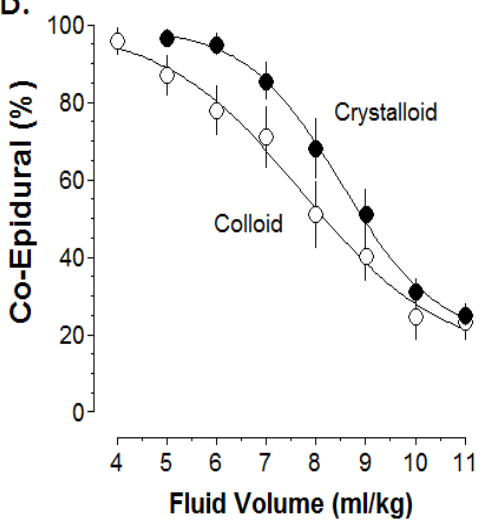

E.

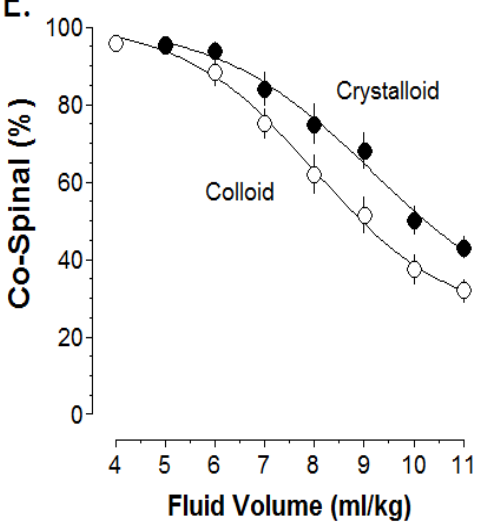

C.

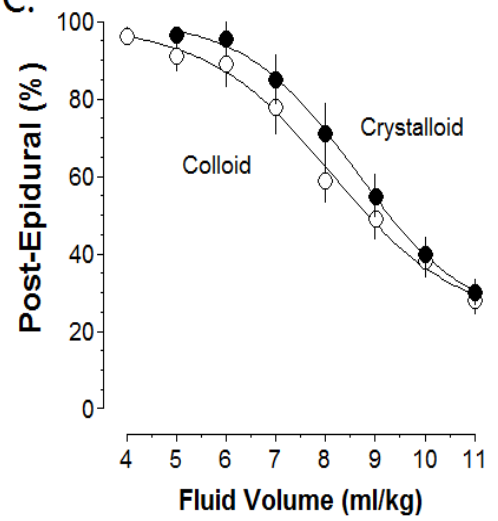

F.

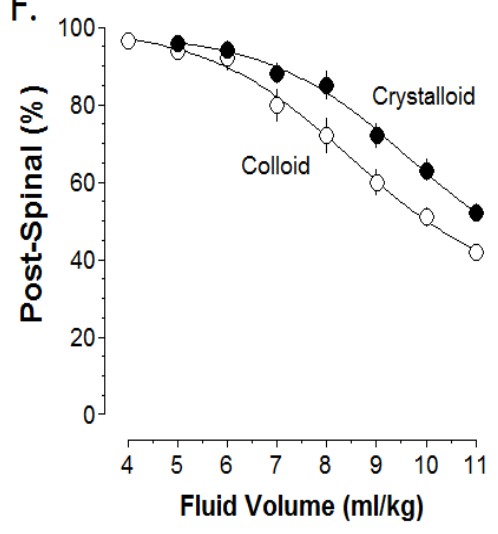

Probabilities of hypotension response to fluid volumes, crystalloid $5-11 \mathrm{ml} / \mathrm{kg}$ and colloid $4-11 \mathrm{ml} / \mathrm{kg}$, analyzed using logistic regression and maximum likelihood estimation of raw data after fitted to a sigmoidal maximum efficacy model. EV50 and EV90 of each curve are calculated and presented in Table 3. Panel A to F display an estimated proportion of the hypotension developed even if a large amount of fluid $(11 \mathrm{ml} / \mathrm{kg})$ was given.

Apgar scores at 1 and 5 min and neurobehavioral assessment scale (NBAS; detailed criteria were listed in Supplementary Materials Table S-3) were rated by the pediatric personnel according to the standard assessment. Umbilical-cord blood gas analysis was performed by the investigators.

\section{Trial Outcomes}

The rate of hypotension with different severity including overall hypotension, clinically significant hypotension (hypotension associated with maternal discomfort defined as nausea, retching/vomiting, dizziness or chest symptoms) and severe hypotension (SBP less than 80 $\mathrm{mmHg}$ ) was selected as the primary outcome of the different fluid intervention procedures in CHOPIN trial. Secondary outcomes include recurrence of hypotension after ephedrine correction, obstetric and anesthetic variables described above as time intervals, total volume of intraoperative fluids with the exception of interventional target fluids, and the incidence of side effects from epidural or spinal puncture and drug delivery. Infant outcomes include the body weight, Apgar scorings, umbilical-cord blood gas measurement and NBAS scales.

\section{Outcome Adjudication}

A committee of physicians who are blinded to the group allocation adjudicated the aforementioned outcomes. We used the decisions from the Adjudication Committee for all statistical analyses involving these outcomes.

\section{Sample Size}




\section{Table 2. Primary Maternal Outcomes.}

\begin{tabular}{|c|c|c|c|}
\hline Outcome & Crystalloid $(n=469)$ & Colloid $(n=470)$ & p Value \\
\hline \multicolumn{4}{|l|}{ Overall hypotension, $\mathbf{n}(\%)$} \\
\hline \multicolumn{4}{|l|}{ Epidural } \\
\hline Pre-loading & $52(11.0)$ & $45(9.6)$ & 0.45 \\
\hline Co-loading & $47(10.0)$ & $42(8.9)$ & 0.57 \\
\hline Post-loading & $49(10.4)$ & $47(10.0)$ & 0.82 \\
\hline \multicolumn{4}{|l|}{ Spinal } \\
\hline Pre-loading & $50(10.7)$ & $34(7.2)$ & 0.066 \\
\hline Co-loading & $54(11.5)$ & $46(9.8)$ & 0.39 \\
\hline Post-loading & $60(12.8)$ & $53(11.3)$ & 0.47 \\
\hline \multicolumn{4}{|l|}{ Clinically significant hypotension, n (\%) * } \\
\hline \multicolumn{4}{|l|}{ Epidural } \\
\hline Pre-loading & $8(15.3)$ & $6(13.3)$ & 0.77 \\
\hline Co-loading & $11(23.4)$ & $7(16.7)$ & 0.43 \\
\hline Post-loading & $9(18.4)$ & $9(19.1)$ & 0.92 \\
\hline \multicolumn{4}{|l|}{ Spinal } \\
\hline Pre-loading & $10(20.0)$ & $8(23.5)$ & 0.69 \\
\hline Co-loading & $12(22.2)$ & $11(23.9)$ & 0.84 \\
\hline Post-loading & $14(23.3)$ & $12(22.6)$ & 0.93 \\
\hline \multicolumn{4}{|l|}{ Severe hypotension, $\mathbf{n}(\%) \dagger$} \\
\hline \multicolumn{4}{|l|}{ Epidural } \\
\hline Pre-loading & $4(7.7)$ & $3(6.7)$ & 0.85 \\
\hline Co-loading & $5(10.6)$ & $4(9.5)$ & 0.86 \\
\hline Post-loading & $6(12.2)$ & 7 (14.9) & 0.70 \\
\hline \multicolumn{4}{|l|}{ Spinal } \\
\hline Pre-loading & $5(10.0)$ & $4(11.8)$ & 0.80 \\
\hline Co-loading & $7(12.9)$ & $6(13.0)$ & 0.99 \\
\hline Post-loading & $8(13.3)$ & $6(11.3)$ & 0.75 \\
\hline \multicolumn{4}{|c|}{ Recurrence of hypotension after ephedrine, $\mathrm{n}(\%) \ddagger$} \\
\hline \multicolumn{4}{|l|}{ Epidural } \\
\hline Pre-loading & $7(13.4)$ & $5(11.1)$ & 0.73 \\
\hline Co-loading & $6(12.8)$ & $6(14.3)$ & 0.83 \\
\hline Post-loading & $8(16.3)$ & $5(10.6)$ & 0.42 \\
\hline \multicolumn{4}{|l|}{ Spinal } \\
\hline Pre-loading & $8(16.0)$ & $5(14.7)$ & 0.87 \\
\hline Co-loading & $9(16.7)$ & $8(17.4)$ & 0.94 \\
\hline Post-loading & $9(15.0)$ & 7 (13.2) & 0.79 \\
\hline
\end{tabular}

* Clinically significant hypotension means the hypotension is associated with maternal discomfort such as nausea, retching/vomiting, dizziness or chest symptoms, and calculated from the overall incidence of hypotension.

† Severe hypotension refers to the systolic blood pressure (SBP) less than $80 \mathrm{mmHg}$. The percentage of severe hypotension was calculated from the overall incidence of hypotension.

‡ Denotes the percentage was calculated from the overall occurrence of hypotension.

According to previously reported studies on the reduction in the cumulative rate of hypotension from regional anesthesia $(29,30)$ and the institutional early database, the mean difference in hypotension decrease was 2.5 per cent, i.e., $17.5 \%$ in the crystalloid group and $20 \%$ in the colloid group under neuraxial anesthesia; we set the two-sided $\alpha=0.05$, one-sided $\beta=0.10$, and the power of test $=0.90$. Therefore, a minimal sample size of 65 subjects per group was needed to detect the difference. We increased the sample size to 75 in each group to account for potential missing data and dropout during the study course. The $15 \%$ increase in sample size was mainly on the basis of the institutional database that round $11 \%$ [median; interquartile range (IQR), 9-15\%] patients dropped out or their data were lost during studying period. Therefore, we increased the sample size to 75 per group following the upper limit 15\%. 


\section{Figure 3. Odds Ratios for Hypotension.}

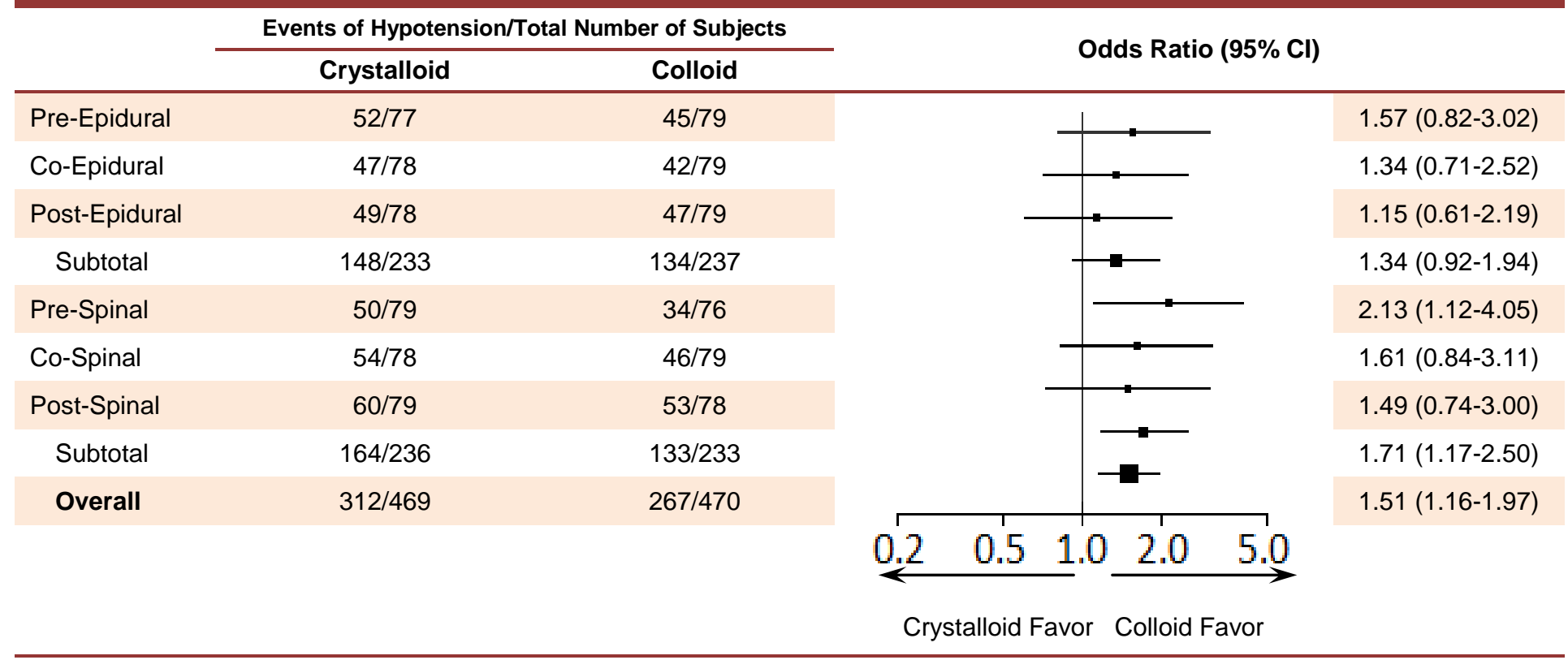

In overall, colloid is better in preventing hypotension than crystalloid with an OR of $1.51,95 \% \mathrm{Cl} 1.16-1.97$.

\section{Statistical Analyses}

Analyses were done using GraphPad Prism version 5.0 (GraphPad Software, Inc., San Diego, CA) or SPSS version 13.0 (SPSS Inc., Chicago, IL). Values are expressed as the mean, SD, IQR, or numbers. All our data assessment primarily was based on an intention-to-treat (ITT) analysis. Meanwhile, a per protocol (PP) analysis was done, in which the subjects excluded, withdrawn, and lost follow-up were precluded. All statistical tests were two-sided and the statistical significance was accepted at the level of $\mathrm{p}<0.05$.

All categorical data were analyzed with a chisquare test or Fisher's exact test (as appropriate) to indicate the trend. The difference in parametric data ere compared with Student $t$ test. The one-way analysis of variance (ANOVA) was used to examine the multigroup differences in the demographic data. The ANOVA tests were always followed by the Bonferroni post hoc tests. Mann-Whitney U test was used in analyzing non Gaussian distributed variables and presented as the medians and IQRs, including gestational age of fetus, the highest sensory block level, time intervals of obstetrics and anesthesia. The number needed to treat (NNT) with repeated ephedrine and corresponding 95\% confidence interval (95\% CI) were calculated based on the absolute risk reduction (ARR): NNT $=1 / A R R$. The ARR was the reduction in the proportion of the patients who developed hypotension in the crystalloid or colloid group after firstly prescribed ephedrine.

Volume-effect data were fitted to a sigmoidal maximum efficacy model by means of GraphPad Prism software. The median effective volume (EV50), 90\% effective volume (EV90) and corresponding 95\% CIs were calculated using maximum likelihood estimation and logistic regression with Firth's correction. Odds ratios (ORs) for hypotension and their 95\% CIs were estimated in the ITT population and in the predefined subgroups with different fluid volumes.

\section{RESULTS}

One thousand gravidas were screened for eligibility and 61 subjects were excluded during the screening period because of the reasons appeared in Figure 1. Of the three patients unsuitable for performing epidural or spinal puncture, two were spinal deformity and one has undergone back surgery at the site of needle insertion. 


\section{Table 3. EV50 and EV90 of Different Interventions.}

\begin{tabular}{|c|c|c|c|c|c|c|}
\hline & \multicolumn{3}{|c|}{$\mathrm{EV}_{50}(95 \% \mathrm{Cl})$} & \multicolumn{3}{|c|}{$\mathrm{EV}_{90}(95 \% \mathrm{Cl})$} \\
\hline & Crystalloid & Colloid & p Value & Crystalloid & Colloid & p Value \\
\hline \multicolumn{7}{|l|}{ Epidural } \\
\hline Pre-loading & $8.37(7.32-9.41)$ & $6.87(6.36-7.39)$ & 0.039 & $9.11(8.72-11.61)$ & $7.52(6.83-9.07)$ & 0.019 \\
\hline Co-loading & $8.51(8.09-8.93)$ & $7.73(6.89-8.58)$ & 0.087 & $9.47(9.01-12.49)$ & $8.03(7.25-11.06)$ & 0.004 \\
\hline Post-loading & $8.62(8.20-9.05)$ & $8.12(7.42-8.84)$ & 0.095 & $9.84(9.25-13.00)$ & 8.88 (7.73-11.82) & 0.017 \\
\hline \multicolumn{7}{|l|}{ Spinal } \\
\hline Pre-loading & $8.66(8.11-9.22)$ & $7.35(7.22-7.49)$ & 0.033 & $9.37(8.69-12.23)$ & $8.54(7.70-10.84)$ & 0.023 \\
\hline Co-loading & $9.21(6.26-12.16)$ & $8.02(7.47-8.56)$ & 0.48 & $10.46(9.52-13.65)$ & $9.09(8.60-12.33)$ & 0.014 \\
\hline Post-loading & $9.67(7.21-12.13)$ & $8.50(7.66-9.34)$ & 0.34 & $12.31(10.47-15.59)$ & $10.58(9.17-13.28)$ & 0.026 \\
\hline
\end{tabular}

EV50: median effective volume; EV90: $90 \%$ effective volume; $95 \% \mathrm{CI}$ : $95 \%$ confidence interval

A total of 939 women were firstly randomized to receive crystalloid or colloid intervention, and then the second- and third-stage randomizations were proceeded to performing epidural or spinal anesthesia with different fluid regimens, of them 33 subjects did not received targeted fluids and seven were lost follow-up because of a discontinued fluid-delivering for the investigators reasons. In the epidural anesthesia, a total of seven participants encountered inadvertent dural puncture without any post-anesthesia treatment. Finally, 469 subjects in the crystalloid group and 470 subjects in the colloid group were analysed. All those excluded patients after randomization were treated as the ITT analysis.

Table 1 summarizes the demographic, background characteristics, and baseline vital signs (all were within the physiologic ranges). They were comparable each other among the subgroups.

Subjects who developed hypotension per study protocol are presented in Table 2, and no statistically significant differences were observed between crystalloid and colloid interventions. The numbers of patients developed clinically significant and severe hypotension are much lower in both fluids than the overall occurrence of hypotension. The percentage of hypotension in different intervention regimens is showed in Figure 2. The EV50 and EV90 of crystalloid and colloid in each subgroup are showed in Table 3 . The volume of colloid required in preventing hypotension either in the epidural or the spinal population is relatively lower than that of crystalloid. In addition, the values of EV50 in pre-loading groups and all the EV90 in three loading regimens showed statistical significance $(\mathrm{p}<0.05)$. Moreover, both EV50 and EV90 of crystalloid and colloid, respectively, appeared a significant increase from pre-loading to co-loading to post-loading subgroup. $\mathrm{Pa}$ - tients who developed hypotension were treated with ephedrine, and repeated ephedrine can be prescribed if the subject encountered hypotension again. The NNTs with repeated ephedrine in different intervention groups were calculated and showed that only in the preloading spinal anesthesia patients who were given less ephedrine in the colloid than that in the crystalloid ( $\mathrm{p}=$ 0.002, see Supplementary Materials Table S-4). Besides, similar results received when analyzing the rate of hypotension on the PP population basis.

There were no statistically significant differences in obstetric and anesthetic data compared between crystalloid and colloid showed in Supplementary Materials Table S-5. Infant outcomes in both intervention fluids showed in Supplementary Materials Table S-6 displayed no significant differences in each subgroup.

In both fluids, patients underwent spinal anesthesia experienced more adverse events than that of epidural anesthesia (38 vs. 27 in spinal and epidural with crystalloid, respectively; 36 vs. 28 in spinal and epidural with colloid, respectively). One patient in the pre-spinal crystalloid underwent hysterectomy because of mass perfuse hemorrhage. But, overall, no statistical significance was observed in the two fluid interventions (see Supplementary Materials Table S-7).

Figure 3 summarizes the ORs of hypotension in the ITT population and in the predefined subgroups with different fluid volumes. The overall effect of colloid on hypotension prevention is superior to crystalloid with an OR 1.51 (95\% CI, 1.16 - 1.97; p = 0.002). Furthermore, we calculated the ORs of hypotension by subdividing the volumes of fluids into three parts, i.e. 57, 7-9 and 9-11 ml/kg of crystalloid, and 4-7, 7-9 and 9$11 \mathrm{ml} / \mathrm{kg}$ of colloid, and found volume of both fluids less 
than $7 \mathrm{ml} / \mathrm{kg}$ had a higher ORs than those over $7 \mathrm{ml} / \mathrm{kg}$ (see Supplementary Materials Figure S-2).

\section{DISCUSSION}

In this study, we calculated the EV50 and EV90 of crystalloid and colloid in preventing hypotension in patients undergoing cesarean delivery with epidural or spinal anesthesia, and compared the effectiveness of both fluids given at different regimens (pre-, co- or postanesthesia loading) in affecting infant outcomes. The median and $90 \%$ effective volumes of colloid are relatively lower by $1.5-2.0 \mathrm{ml} / \mathrm{kg}$ compared with crystalloid when reaching similar role in balancing circulation by preventing the occurrence of hypotension in cesarean parturients undergoing neuraxial block, and both crystalloid and colloid produced little influence on infant outcomes. Overall, colloid is superior to crystalloid in hypotension prevention with an OR of 1.51 (95\% CI 1.16-1.97).

Volumes of fluids, crystalloid or colloid, given for against regional anesthesia-induced hypotension in cesarean section has been discussing for decades, but the precise volumes how much can produce optimal effect are still not reached $(16-19,31)$. Those who praise the 'liberal' fluid therapy suggested that the augmentation of blood volume with pre-loading, regardless of the fluid used, must be large enough to result in a significant increase in cardiac output for effective prevention of hypotension, and in their studies, at least 1,500-2,000 ml crystalloid or 1,000 ml colloid was recommended (11-13, 32). Nevertheless, the 'restricted' party considered that extreme expansion of the blood volume with prophylactic fluids would exert negative effects on maternal and infant outcomes, thus they proposed a relative lower volume of fluids, i.e. $1,000 \mathrm{ml}$ crystalloid or $500 \mathrm{ml}$ colloid was good enough (33-35). In addition, contrary data demonstrated that no matter what type or what volume of fluids infused, the incidence of hypotension appeared without significant difference between crystalloid and colloid, and in both high and low dose of volumes (18, $23,36)$. All these studies used an estimated volume of fluids. In our study, we calculated the EV50 and EV90 of crystalloid and colloid in different study protocols, and found that both EV50 and EV90 of crystalloid are higher than those of colloid in the two types of anesthetized population. Besides, patients underwent spinal anesthesia required more fluids than whom with epidural anesthesia. The possible reason for such a difference is mainly because epidural block needs longer time when the local anesthetic diffusing and reaching the spinal cord through the meninges than spinal anesthesia alone (37). Therefore, epidural anesthesia allows patients with more time to adapt and endure the sympathetic blockade-induced decrease in blood pressure or fluctuation of circulation, but spinal anesthesia with rapid onset of blockade cannot give enough time to do so.

Pre-loading regimen of fluids is recommended for its prophylactic role of hypotension through prior augmentation of the circulation, though, recent studies displayed similar effect of co-loading and post-loading maneuvers in against the incidence of hypotension $(17,18$, 38). Williamson et al. suggested the combined method of pre-loading and co-loading means as a substitute for the simple pre-loading crystalloid fluid administration (19). In our study, three fluid-delivering protocols produced similar effect on the reduction of hypotension when they reached corresponding effective volumes. This is also the major difference of our study from previous reports because we used a volume-incremental manner to realize an optimal effect of hypotension prevention, but not merely a fixed volume of fluids. This design, on the one hand, can increase the sensitivity of the study intervention by enlarging the selective window; and on the other hand, additional outcome analyses can still be performed as the traditional design did.

Hypotension is the major manifest of circulation imbalance induced by neuraxial anesthesia, from which series of maternal and neonatal severe adverse events can result (3-6). While clinical guidelines recommend a prophylactic administration of fluids for preventing this complication, different studies displayed controversial results on this issue, i.e. in effect versus in vain. Dyer and colleagues considered that the timing of fluid administration is the reason for ineffectiveness of traditional pre-loading method with an over (20) min period of fluid titration before anesthesia induction, and they emphasized a rapid crystalloid infusion after spinal anesthesia (21). Dahlgren et al. found that parturients with a positive preoperative supine stress test are more easily developed clinically significant hypotension than the negative comparisons, and the stress positive women are more likely to benefit from prophylactic colloid solution than the negative ones (39). In addition, they also found that the more severe of hypotension the patients encountered, the more protective effect of the colloid solution appeared in spinal anesthetized women (13). As 
Ueyama et al. presented that large dose of fluid can effectively prevent the occurrence of hypotension, but a rate of hypotension at least $15 \%$ was still observed in those received large-dose colloid (12). This is in accordance with the results of a systematic review (40) that colloid administration is the effective means of hypotension prevention, though, it still cannot totally eliminates the occurrence of this anesthesia-associated complication. In our study, crystalloid and colloid given with different loading regimens all produce effective role in preventing hypotension, especially in the clinically significant and severe hypotension, but, overall, there is yet an occurrence of hypotension at a rate of about $10 \%$ to $20 \%$ even when the EV90 was reached. Besides, the NNTs with repeated ephedrine in the colloid participants are much lower compared with the crystalloid ones, especially in the pre-spinal loading patients.

Neonatal outcomes are major consideration for cesarean parturients under regional anesthesia due to the threatening from hypotension, but recent literatures showed that despite the high prevalence of maternal hypotension, term infants can tolerate this placental blood perfusion challenge without any major negative consequences (41-43). Meanwhile, a range of studies also did not find any sequel from the fluid interventions in patients undergoing cesarean section with neuraxial blockade (36, 44-47). Our results are consistent with these findings that various fluid loadings produced little effect on infants' Apgar and NBAS scorings, and also no significant difference was observed in the umbilicalcord artery $\mathrm{pH}$ values in both crystalloid and colloid.

Maternal adverse events in each loading group were recorded and found that nausea/vomiting, fatigue, itching and shivering are four major events in both fluid interventions. Although one woman in the co-spinal colloid loading regimen found with mild pulmonary edema, this does not seem to be associated with colloid administration because the women merely received 7 $\mathrm{ml} / \mathrm{kg}$ fluid and no intraoperative hypotension developed diagnosed with following clinical manifestations: breathing difficulty especially shortness of breath worse on lying down, lung crackling sounds in stethoscope, and positive results in chest X-ray; and recovered after treating with diuretics, morphine sulphate and antibiotics. The incidences of adverse events are similar in all types of fluid loadings.

In summary, this study provides robust evidence that the hypotension-preventing effect of both crystalloid and colloid in parturients undergoing cesarean delivery with neuraxial anesthesia is reliable, and this effect displays a volume-dependent manner in a limited scope, of which is concordant with other previous reports that large amount of fluids are not necessarily useful in balancing maternal hemodynamic $(22,48)$. Second, different fluid loading regimens have their own corresponding EV50 and EV90 for stabilizing circulation under different regional anesthesia, epidural or spinal, but not the traditionally used means of crystalloid $1,000 \mathrm{ml}$ or colloid $500 \mathrm{ml}$. At last, while fluid loading is an effective method of preventing neuraxial block-induced hypotension in cesarean parturients, it cannot total eliminate its occurrence with a final rate of $10 \%$ to $20 \%$ as suggested by a systematic review that surgical procedures should not be delayed regardless of the fluid loading strategy because the incidence of maternal hypotension is still high (49). Therefore, fluid loading is an effective maneuver in balancing maternal circulation when reaching the effective volume of different neuraxial anesthesia, but prophylactic or therapeutic vasopressors should also be prepared and be given at an appropriate time because a significant proportion of parturients can still develop hypotension.

\section{ARTICLE INFORMATION}

Author Affiliations: Department of Anesthesiology, Hospital of Obstetrics \& Gynecology, Affiliated to Nanjing Medical University, Nanjing, China (Xu, Wang, Wu, Wang, Fu, Liu, Wang, Xia, Feng, sHEN); Department of Anesthesiology, Shanghai First Maternity and In- fant Hospital, Tongji University School of Medicine, Shanghai 201204, China (Zhao).

Author Contributions: Shen had full access to all of the data in the study and take responsibility for the integrity of the data and the accuracy of the data analysis.
Study concept and design: Xu \& Shen Acquisition, analysis, or interpretation of data: $\mathrm{Xu}$, Zhao, Wang and Wu.

Drafting of the manuscript: Xu and Zhao. Critical revision of the manuscript for important intellectual content: Shen. Statistical analysis: Xu, Zhao, Wang, and Wu. 
Obtained funding: N/A.

Administrative, technical, or material support: Shen.

Study supervision: Shen.

Conflict of Interest Disclosures: The author declared no competing interests of this manuscript submitted for publication.

Acknowledgement: The authors thank all obstetricians, pediatricians, nurses and anesthesiologists who participated in collecting the data in our hospital, and are gratitude for the generous help for the statistical work from all statisticians at the Nanjing Medical University, Nanjing, China, as well as the Data Monitoring Committee, Adverse Event Advisory Committee and Outcome Adjudicating Committee.

Funding/Support: None. Role of the Funder/Sponsor: N/A.

How to Cite This Paper: Xu S, Zhao Q, Wang F, Wu H, Wang W, Fu D, Liu Y, Wang X, Xia F, Feng $S$, Shen $X$. Crystalloid versus colloid in stabilizing hemodynamic of patients undergoing Cesarean section with neuraxial anesthesia: a randomized controlled trial. Sci Insigt. 2019; 2019:e0012.

Digital Object Identifier (DOI): http://dx.doi.org/10.15354/si.19.ar009.

Article Submission Information: Received, September 16, 2018; Revised: November 15, 2018; Accepted: November 27, 2018.

\section{REFERENCES}

1. Benhamou D, Wong C. Neuraxial anesthesia for cesarean delivery: what criteria define the "optimal" technique? Anesth Analg 2009; 109 : 1370-1373.

2. Ng K, Parsons J, Cyna AM, Middleton $P$. Spinal versus epidural anesthesia for cesarean section. Cochrane Database Syst Rev 2004; 2: CD003765.

3. Nobili C, Sofi G, Bisicchia C. Prevention of hypotension in spinal anesthesia carried out for cesarean section. Minerva Anestesiol 2003; 69: 392-401.

4. Alexander AM, Lobrano S. Perimortem Cesarean Delivery. StatPearls [Internet]. Treasure Island (FL): StatPearls Publishing; 2018.

5. Balki M, Carvalho JC. Intraoperative nausea and vomiting during cesarean section under regional anesthesia. Int J Obstet Anesth 2005; 14: 230241.

6. Abdelazim I, Alanwar A, Svetlana S, Sakiyeva K, Farghali M, Mohamed M, Zhurabekova G, Karimova B. Complications associated with higher order compared to lower order cesarean sections. J Matern Fetal Neonatal Med 2018:1-161.

7. Mendonca C, Griffiths J, Ateleanu B, Collis RE. Hypotension following combined spinal-epidural anesthesia for Cesarean section. Left lateral position vs. tilted supine position. Anesthesia 2003; 58: 428-431.

8. Bjørnestad E, Iversen OE, Raeder J. Wrapping of the legs versus phenylephrine for reducing hypotension in parturients having epidural anesthesia for cesarean section: a prospective, randomized and double- blind study. Eur J Anesthesiol 2009; 26: 842-846.

9. Bannard-Smith J, Yuill G, Washington SJ. Which vasopressor for cesarean section? Br J Hosp Med (Lond) 2009; 70: 725.

10. Mohta M, Agarwal D, Gupta LK, Sethi AK, Tyagi A. Potency of mephentermine for prevention of post-spinal hypotension. Anaesth Intensive Care 2009; 37: 568-570.

11. Murray AM, Morgan M, Whitwam JG Crystalloid versus colloid for circulatory preload for epidural cesarean section. Anesthesia 1989; 44: 463466.

12. Ueyama $\mathrm{H}, \mathrm{He} \mathrm{YL}$, Tanigami $\mathrm{H}$, Mashimo T, Yoshiya I. Effects of crystalloid and colloid preload on blood volume in the parturient undergoing spinal anesthesia for elective Cesarean section. Anesthesiology 1999; 91: 1571-1576.

13. Dahlgren $G$, Granath F, Pregner K, Rösblad PG, Wessel H, Irestedt L. Colloid vs. crystalloid preloading to prevent maternal hypotension during spinal anesthesia for elective cesarean section. Acta Anesthesiol Scand 2005; 49: 1200-1206.

14. Ko JS, Kim CS, Cho HS, Choi DH. A randomized trial of crystalloid versus colloid solution for prevention of hypotension during spinal or low-dose combined spinal-epidural anesthesia for elective cesarean delivery. Int $\mathrm{J}$ Obstet Anesth 2007; 16: 8-12.

15. Tamilselvan P, Fernando R, Bray J, Sodhi M, Columb M. The effects of crystalloid and colloid preload on cardiac output in the parturient undergoing planned cesarean delivery under spinal anesthesia: a random- ized trial. Anesth Analg 2009; 109: 1916-1921.

16. Teoh WH, Sia AT. Colloid preload versus coload for spinal anesthesia for cesarean delivery: the effects on maternal cardiac output. Anesth Analg 2009; 108: 1592-1598.

17. Carvalho B, Mercier FJ, Riley ET, Brummel C, Cohen SE. Hetastarch co-loading is as effective as preloading for the prevention of hypotension following spinal anesthesia for cesarean delivery. Int J Obstet Anesth 2009; 18: 150-155.

18. Siddik-Sayyid SM, Nasr VG, Taha SK, Zbeide RA, Shehade JM, Al Alami AA, Mokadem FH, Abdallah FW, Baraka AS, Aouad MT. A randomized trial comparing colloid preload to coload during spinal anesthesia for elective cesarean delivery. Anesth Analg 2009; 109: 1219-1224.

19. Williamson W, Burks D, Pipkin J, Burkard JF, Osborne LA, Pellegrini JE. Effect of timing of fluid bolus on reduction of spinal-induced hypotension in patients undergoing elective cesarean delivery. AANA J 2009; 77: 130-136.

20. Rout CC, Akoojee SS, Rocke DA, Gouws E. Rapid administration of crystalloid preload does not decrease the incidence of hypotension after spinal anesthesia for elective cesarean section. Brit J Anaesth 1992; 68: 394-397.

21. Dyer RA, Farina $Z$, Joubert IA, Du Toit P, Meyer M, Torr G, Wells K, James MF. Crystalloid preload versus rapid crystalloid administration after induction of spinal anesthesia (coload) for elective cesarean section. Anaesth Intensive Care 2004; 32: 351-357. 
22. Park GE, Hauch MA, Curlin F, Datta $S$, Bader AM. The effects of varying volumes of crystalloid administration before cesarean delivery on maternal hemodynamics and colloid osmotic pressure. Anesth Analg 1996; 83: 299-303.

23. Muzlifah KB, Choy YC. Comparison between preloading with $10 \mathrm{ml} / \mathrm{kg}$ and $20 \mathrm{ml} / \mathrm{kg}$ of Ringer's lactate in preventing hypotension during spinal anesthesia for cesarean section. Med J Malaysia 2009; 64: 114-117.

24. National Collaborating Centre for Women's and Children's Health. Cesarean section: anesthesia for CS. Guideline for National Institute for Clinical Excellence (NICE). Royal College of Obstetricians and Gynaecologists (RCOG) press. 2004; pp56pp61.

25. American Society of Anesthesiologists Task Force on Obstetric Anesthesia. Practice guidelines for obstetric anesthesia: an updated report by the American Society of Anesthesiologists Task Force on Obstetric Anesthesia. Anesthesiology 2007; 106: 843-863.

26. Cyna AM, Andrew M, Emmett RS, Middleton P, Simmons SW. Techniques for preventing hypotension during spinal anesthesia for cesarean section. Cochrane Database Syst Rev 2006; 4: CD002251.

27. Pace NL, Stylianou MP. Advances in and limitations of up-and-down methodology: a précis of clinical use, study design, and dose estimation in anesthesia research. Anesthesiology 2007; 107: 144-152.

28. George RB, McKeen D, Columb MO, Habib AS. Up-down determination of the $90 \%$ effective dose of phenylephrine for the treatment of spinal anesthesia-induced hypotension in parturients undergoing cesarean delivery. Anesth Analg 2010; 110: 154158.

29. Lewis $M$, Thomas $P$, Wilkes RG. Hypotension during epidural analgesia for Cesarean section. Arterial and central venous pressure changes after acute intravenous loading with two litres of Hartmann's solution. Anesthesia 1983; 38: 250-253.
30. Chan WS, Irwin MG, Tong WN, Lam $\mathrm{YH}$. Prevention of hypotension during spinal anesthesia for cesarean section: ephedrine infusion versus fluid preload. Anesthesia 1997; 52: 908913.

31. Watson CB. Colloid or crystalloid? Anesth Analg 1981; 60: 228-9.

32. Vercauteren MP, Hoffmann V, Coppejans HC, Van Steenberge AL, Adriaensen HA. Hydroxyethylstarch compared with modified gelatin as volume preload before spinal anesthesia for Cesarean section. $\mathrm{Br} \mathrm{J}$ Anaesth 1996; 76: 731-733.

33. Butwick A, Carvalho B. The effect of colloid and crystalloid preloading on thromboelastography prior to Cesarean delivery. Can J Anaesth 2007; 54: 190-195.

34. Cardoso MM, Bliacheriene S, Freitas CR, César DS, Torres ML. Preload during spinal anesthesia for cesarean section: comparison between crystalloid and colloid solutions. Rev Bras Anestesiol 2004; 54: 781-787.

35. Siddik SM, Aouad MT, Kai GE, Sfeir MM, Baraka AS. Hydroxyethylstarch $10 \%$ is superior to Ringer's solution for preloading before spinal anesthesia for Cesarean section. Can J Anaesth 2000; 47: 616-621.

36. Tercanli S, Schneider M, Visca E, Hösli I, Troeger C, Peukert R, Holzgreve W. Influence of volume preloading on uteroplacental and fetal circulation during spinal anesthesia for cesarean section in uncomplicated singleton pregnancies. Fetal Diagn Ther 2002; 17: 142-146.

37. Eltzschig HK, Lieberman ES, Camann WR. Regional anesthesia and analgesia for labor and delivery. N Engl J Med 2003; 348: 319-332.

38. Nishikawa K, Yokoyama N, Saito S, Goto F. Comparison of effects of rapid colloid loading before and after spinal anesthesia on maternal hemodynamics and neonatal outcomes in cesarean section. J Clin Monit Comput 2007; 21: 125-129.

39. Dahlgren G, Granath F, Wessel H, Irestedt L. Prediction of hypotension during spinal anesthesia for Cesarean section and its relation to the effect of crystalloid or colloid preload.
Int J Obstet Anesth 2007; 16: 128 134.

40. Morgan PJ, Halpern SH, Tarshis J. The effects of an increase of central blood volume before spinal anesthesia for cesarean delivery: a qualitative systematic review. Anesth Analg 2001; 92: 997-1005.

41. Maayan-Metzger A, Schushan-Eisen I, Todris L, Etchin A, Kuint J. Maternal hypotension during elective cesarean section and short-term neonatal outcome. Am J Obstet Gynecol 2010; 202: 56.e1-e5.

42. Blackwell SC, Pacheco L, Chiossi G, Lee T, Nguyen T. Maternal hypotension during cesarean section: Maayan-Metzger et al. Am J Obstet Gynecol 2010; 202: 93-94.

43. Blackwell SC, Pacheco L, Chiossi G, Lee T, Nguyen T. Discussion: 'Maternal hypotension during cesarean section' by Maayan-Metzger et al. Am J Obstet Gynecol 2010; 202: e12-e14.

44. Barbier P, Jonville AP, Autret E, Coureau C. Fetal risks with dextrans during delivery. Drug Saf 1992; 7: 71-73.

45. Karinen J, Räsänen J, Paavilainen T, Alahuhta S, Jouppila R, Jouppila P. Uteroplacental and fetal haemodynamics and cardiac function of the fetus and newborn after crystalloid and colloid preloading for extradural cesarean section anesthesia. Br J Anaesth 1994; 73: 751-757.

46. Littleford J. Effects on the fetus and newborn of maternal analgesia and anesthesia: a review. Can J Anaesth 2004; 51: 586-609.

47. Chanimov M, Gershfeld S, Cohen ML, Sherman D, Bahar M. Fluid preload before spinal anesthesia in Cesarean section: the effect on neonatal acid-base status. Eur $\mathrm{J}$ Anesthesiol 2006; 23: 676-679.

48. Jackson R, Reid JA, Thorburn J. Volume preloading is not essential to prevent spinal-induced hypotension at cesarean section. $\mathrm{Br} \mathrm{J}$ Anaesth 1995; 75: 262-265.

49. Banerjee A, Stocche RM, Angle P, Halpern SH. Preload or coload for spinal anesthesia for elective Cesarean delivery: a meta-analysis. Can J Anaesth 2010; 57: 24-31.. 


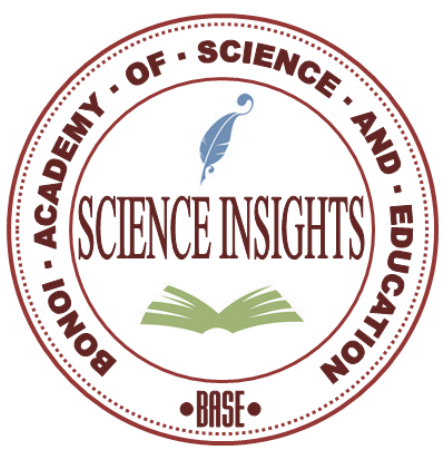

SCIENCE INSIGHTS ${ }^{\circ}$

\section{Supplementary Materials}

\section{Crystalloid versus Colloid in Stabilizing Hemodynamic of Patients Undergoing Cesarean Section with Neuraxial Anesthesia A Randomized Controlled Trial}

By Shiqin Xu, M.D., M.P.H. Qingsong Zhao, M.D. Fuzhou Wang, M.D., Ph.D. Haibo Wu, M.Sc.,Wei Wang, M.D., M.Sc. Dongying Fu, B.Nr. Yusheng Liu, M.D., M.Sc. Xian Wang, M.D., Ph.D., Fan Xia, M.D. Shanwu Feng, M.D., Ph.D. Xiaofeng Shen, M.D., M.P.H.

Sci Insigt. 2019; 2019:e0012. doi:10.15354/si.19.ar009 
Table S-1. Number of Patients Randomized into Different Subgroups.

\begin{tabular}{|c|c|c|}
\hline \multicolumn{3}{|l|}{ Total randomisation $(\mathrm{n}=939)$} \\
\hline \multicolumn{3}{|l|}{ Crystalloid intervention $(n=469)$} \\
\hline \multicolumn{3}{|l|}{ Epidural group $(n=233)$} \\
\hline Pre-epidural part $(\mathrm{n}=77)$ & Co-epidural part $(\mathrm{n}=78)$ & Post-epidural part $(\mathrm{n}=78)$ \\
\hline $5 \mathrm{ml} / \mathrm{kg}(\mathrm{n}=8)$ & $5 \mathrm{ml} / \mathrm{kg}(\mathrm{n}=7)$ & $5 \mathrm{ml} / \mathrm{kg}(\mathrm{n}=5)$ \\
\hline $6 \mathrm{ml} / \mathrm{kg}(\mathrm{n}=7)$ & $6 \mathrm{ml} / \mathrm{kg}(\mathrm{n}=9)$ & $6 \mathrm{ml} / \mathrm{kg}(\mathrm{n}=9)$ \\
\hline $7 \mathrm{ml} / \mathrm{kg}(\mathrm{n}=17)$ & $7 \mathrm{ml} / \mathrm{kg}(\mathrm{n}=14)$ & $7 \mathrm{ml} / \mathrm{kg}(\mathrm{n}=16)$ \\
\hline $8 \mathrm{ml} / \mathrm{kg}(\mathrm{n}=13)$ & $8 \mathrm{ml} / \mathrm{kg}(\mathrm{n}=18)$ & $8 \mathrm{ml} / \mathrm{kg}(\mathrm{n}=17)$ \\
\hline $9 \mathrm{ml} / \mathrm{kg}(\mathrm{n}=14)$ & $9 \mathrm{ml} / \mathrm{kg}(\mathrm{n}=12)$ & $9 \mathrm{ml} / \mathrm{kg}(\mathrm{n}=16)$ \\
\hline $10 \mathrm{ml} / \mathrm{kg}(\mathrm{n}=10)$ & $10 \mathrm{ml} / \mathrm{kg}(\mathrm{n}=11)$ & $10 \mathrm{ml} / \mathrm{kg}(\mathrm{n}=9)$ \\
\hline $11 \mathrm{ml} / \mathrm{kg}(\mathrm{n}=8)$ & $11 \mathrm{ml} / \mathrm{kg}(\mathrm{n}=7)$ & $11 \mathrm{ml} / \mathrm{kg}(\mathrm{n}=6)$ \\
\hline \multicolumn{3}{|l|}{ Spinal group $(n=236)$} \\
\hline Pre-spinal part $(n=79)$ & Co-spinal part $(n=78)$ & Post-spinal part $(\mathrm{n}=79)$ \\
\hline $5 \mathrm{ml} / \mathrm{kg}(\mathrm{n}=7)$ & $5 \mathrm{ml} / \mathrm{kg}(\mathrm{n}=9)$ & $5 \mathrm{ml} / \mathrm{kg}(\mathrm{n}=6)$ \\
\hline $6 \mathrm{ml} / \mathrm{kg}(\mathrm{n}=9)$ & $6 \mathrm{ml} / \mathrm{kg}(\mathrm{n}=6)$ & $6 \mathrm{ml} / \mathrm{kg}(\mathrm{n}=11)$ \\
\hline $7 \mathrm{ml} / \mathrm{kg}(\mathrm{n}=13)$ & $7 \mathrm{ml} / \mathrm{kg}(\mathrm{n}=15)$ & $7 \mathrm{ml} / \mathrm{kg}(\mathrm{n}=17)$ \\
\hline $8 \mathrm{ml} / \mathrm{kg}(\mathrm{n}=18)$ & $8 \mathrm{ml} / \mathrm{kg}(\mathrm{n}=14)$ & $8 \mathrm{ml} / \mathrm{kg}(\mathrm{n}=13)$ \\
\hline $9 \mathrm{ml} / \mathrm{kg}(\mathrm{n}=15)$ & $9 \mathrm{ml} / \mathrm{kg}(\mathrm{n}=19)$ & $9 \mathrm{ml} / \mathrm{kg}(\mathrm{n}=18)$ \\
\hline $10 \mathrm{ml} / \mathrm{kg}(\mathrm{n}=9)$ & $10 \mathrm{ml} / \mathrm{kg}(\mathrm{n}=10)$ & $10 \mathrm{ml} / \mathrm{kg}(\mathrm{n}=8)$ \\
\hline $11 \mathrm{ml} / \mathrm{kg}(\mathrm{n}=8)$ & $11 \mathrm{ml} / \mathrm{kg}(\mathrm{n}=5)$ & $11 \mathrm{ml} / \mathrm{kg}(\mathrm{n}=6)$ \\
\hline \multicolumn{3}{|l|}{ Colloid intervention $(n=470)$} \\
\hline \multicolumn{3}{|l|}{ Epidural group $(n=237)$} \\
\hline Pre-epidural part $(\mathrm{n}=79)$ & Co-epidural part $(n=79)$ & Post-epidural part $(n=79)$ \\
\hline $4 \mathrm{ml} / \mathrm{kg}(\mathrm{n}=5)$ & $4 \mathrm{ml} / \mathrm{kg}(\mathrm{n}=7)$ & $4 \mathrm{ml} / \mathrm{kg}(\mathrm{n}=4)$ \\
\hline $5 \mathrm{ml} / \mathrm{kg}(\mathrm{n}=9)$ & $5 \mathrm{ml} / \mathrm{kg}(\mathrm{n}=7)$ & $5 \mathrm{ml} / \mathrm{kg}(\mathrm{n}=8)$ \\
\hline $6 \mathrm{ml} / \mathrm{kg}(\mathrm{n}=15)$ & $6 \mathrm{ml} / \mathrm{kg}(\mathrm{n}=9)$ & $6 \mathrm{ml} / \mathrm{kg}(\mathrm{n}=11)$ \\
\hline $7 \mathrm{ml} / \mathrm{kg}(\mathrm{n}=11)$ & $7 \mathrm{ml} / \mathrm{kg}(\mathrm{n}=15)$ & $7 \mathrm{ml} / \mathrm{kg}(\mathrm{n}=13)$ \\
\hline $8 \mathrm{ml} / \mathrm{kg}(\mathrm{n}=16)$ & $8 \mathrm{ml} / \mathrm{kg}(\mathrm{n}=13)$ & $8 \mathrm{ml} / \mathrm{kg}(\mathrm{n}=11)$ \\
\hline $9 \mathrm{ml} / \mathrm{kg}(\mathrm{n}=10)$ & $9 \mathrm{ml} / \mathrm{kg}(\mathrm{n}=12)$ & $9 \mathrm{ml} / \mathrm{kg}(\mathrm{n}=16)$ \\
\hline $10 \mathrm{ml} / \mathrm{kg}(\mathrm{n}=6)$ & $10 \mathrm{ml} / \mathrm{kg}(\mathrm{n}=9)$ & $10 \mathrm{ml} / \mathrm{kg}(\mathrm{n}=11)$ \\
\hline $11 \mathrm{ml} / \mathrm{kg}(\mathrm{n}=7)$ & $11 \mathrm{ml} / \mathrm{kg}(\mathrm{n}=7)$ & $11 \mathrm{ml} / \mathrm{kg}(\mathrm{n}=5)$ \\
\hline \multicolumn{3}{|l|}{ Spinal group ( $n=233$ ) } \\
\hline Pre-spinal part $(\mathrm{n}=76)$ & Co-spinal part $(\mathrm{n}=79)$ & Post-spinal part $(\mathrm{n}=78)$ \\
\hline $4 \mathrm{ml} / \mathrm{kg}(\mathrm{n}=6)$ & $4 \mathrm{ml} / \mathrm{kg}(\mathrm{n}=5)$ & $4 \mathrm{ml} / \mathrm{kg}(\mathrm{n}=7)$ \\
\hline $5 \mathrm{ml} / \mathrm{kg}(\mathrm{n}=4)$ & $5 \mathrm{ml} / \mathrm{kg}(\mathrm{n}=5)$ & $5 \mathrm{ml} / \mathrm{kg}(\mathrm{n}=5)$ \\
\hline $6 \mathrm{ml} / \mathrm{kg}(\mathrm{n}=8)$ & $6 \mathrm{ml} / \mathrm{kg}(\mathrm{n}=10)$ & $6 \mathrm{ml} / \mathrm{kg}(\mathrm{n}=9)$ \\
\hline $7 \mathrm{ml} / \mathrm{kg}(\mathrm{n}=12)$ & $7 \mathrm{ml} / \mathrm{kg}(\mathrm{n}=15)$ & $7 \mathrm{ml} / \mathrm{kg}(\mathrm{n}=14)$ \\
\hline $8 \mathrm{ml} / \mathrm{kg}(\mathrm{n}=16)$ & $8 \mathrm{ml} / \mathrm{kg}(\mathrm{n}=13)$ & $8 \mathrm{ml} / \mathrm{kg}(\mathrm{n}=15)$ \\
\hline $9 \mathrm{ml} / \mathrm{kg}(\mathrm{n}=15)$ & $9 \mathrm{ml} / \mathrm{kg}(\mathrm{n}=17)$ & $9 \mathrm{ml} / \mathrm{kg}(\mathrm{n}=14)$ \\
\hline $10 \mathrm{ml} / \mathrm{kg}(\mathrm{n}=7)$ & $10 \mathrm{ml} / \mathrm{kg}(\mathrm{n}=8)$ & $10 \mathrm{ml} / \mathrm{kg}(\mathrm{n}=9)$ \\
\hline $11 \mathrm{ml} / \mathrm{kg}(\mathrm{n}=8)$ & $11 \mathrm{ml} / \mathrm{kg}(\mathrm{n}=6)$ & $11 \mathrm{ml} / \mathrm{kg}(\mathrm{n}=5)$ \\
\hline
\end{tabular}


Table S-2. Contraindications for Neuraxial Anesthesia.

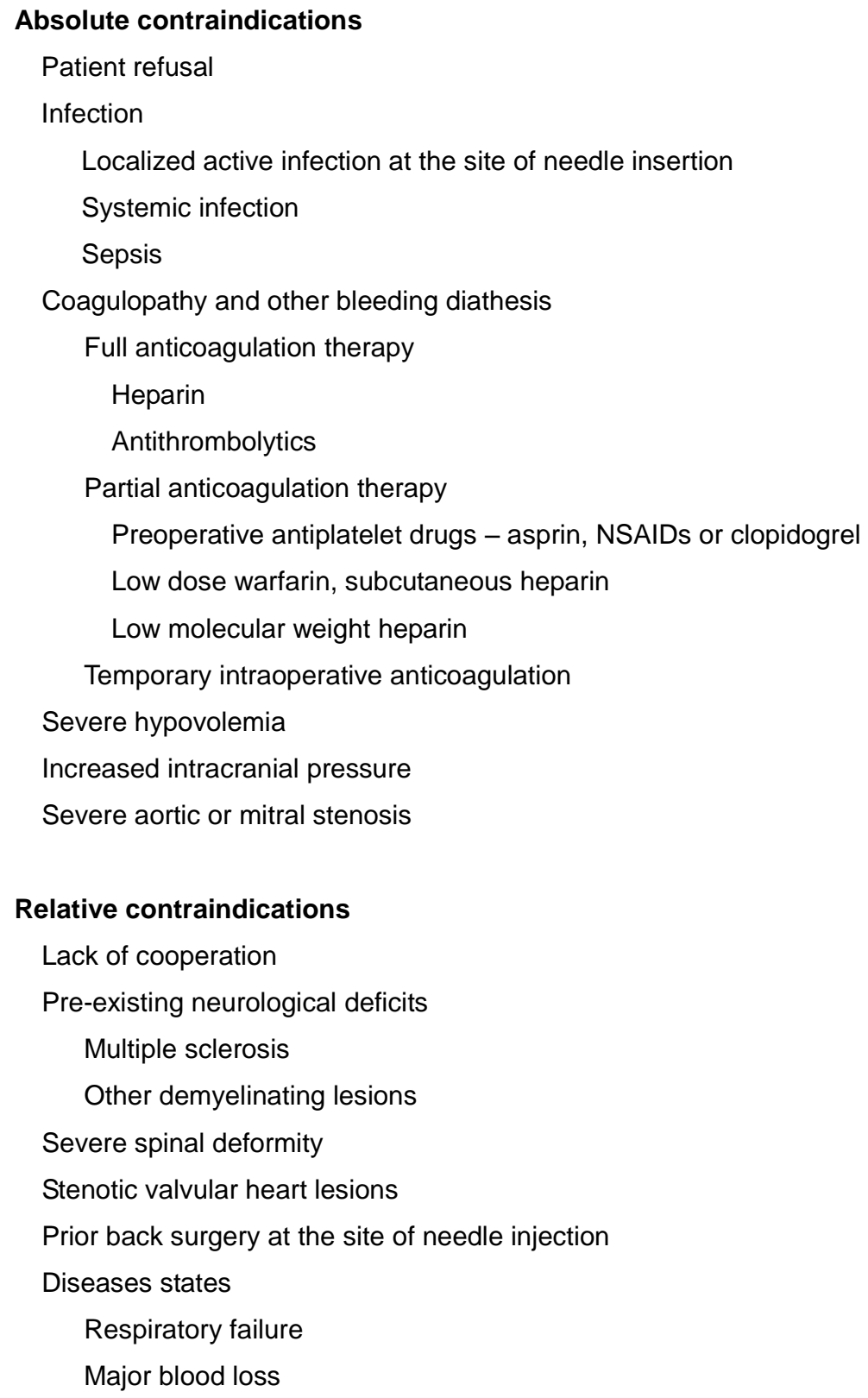

\section{Relative contraindications}

Lack of cooperation

Pre-existing neurological deficits

Multiple sclerosis

Other demyelinating lesions

Severe spinal deformity

Stenotic valvular heart lesions

Prior back surgery at the site of needle injection

Diseases states

Respiratory failure

Major blood loss

NSAIDs: non-steroidal anti-inflammatory drugs 


\section{Table S-3. Criteria for NBAS Scale. *}

The Neurobehavioral Assessment Scale (NBAS) is intended to test the modifiability of an infant's performance in response to activities specific to the newborn or young infant. The NBAS can be used for neurobehavioral examination over the first months of life (0-18 months). Its underlying principles can be applied at any age. Note that each score indexes the quality of the infant's performance and the responsiveness of the infant to the maneuvers performed by the examiner. The examiner does not just carry out standard maneuvers to obtain responses (reflexes) which are judged normal or abnormal according to a standard criterion. The examiner plays an active role modifying his/her behavior in order to elicit the infant's 'best performance'. In this way the NBAS tests the modifiability of the infant's performance in response to changes of environmental inputs, i.e. affordances and the examiner's scaffolding behavior. This procedure permits the examiner to test the effectiveness of his/her maneuvers in modifying the infant's performance. Below the 11 neurobehavioral areas assessed are illustrated with the descriptions of the extreme scores.

\begin{tabular}{|c|c|c|}
\hline No. & Item & Criterion \\
\hline 1 & Autonomic System Control & $\begin{array}{l}\text { A score of } 1 \text { is assigned when the infant shows good autonomic control during the entire examination. No change in skin color or } \\
\text { respiratory rate is observed. By contrast, a score of } 5 \text { is given when the infant is never able to control his autonomic subsystem, } \\
\text { not even following prolonged examiner attempts to console him/her. }\end{array}$ \\
\hline 2 & Behavioral Stale Control & $\begin{array}{l}\text { A score of } 1 \text { is assigned when the infant shows a prompt reaction to the more disturbing maneuvers. Although he will eventually } \\
\text { reach a crying state, he is able to self quiet or be comforted by minimal examiner intervention (face or voice) and achieves an alert } \\
\text { state. By contrast, a score of } 5 \text { is given when the infant shows a noncontrollable alteration in his behavioral states. Consolation is } \\
\text { not achieved, even following prolonged examiner attempts. }\end{array}$ \\
\hline 3 & Motor Activity Control & $\begin{array}{l}\text { A score of } 1 \text { is given when startles, tremors and clonus are practically absent throughout the entire examination, or if present, do } \\
\text { not influence the infant's performances and thus do not alter behavioral, autonomic and orientation responses. Motor activity is } \\
\text { fluent and active for most of the exam. By contrast, a score of } 5 \text { is given when control is never reached. }\end{array}$ \\
\hline 4 & $\begin{array}{l}\text { Visual and Auditory Orientation } \\
\text { (Interactive/Attention Subsystem) }\end{array}$ & $\begin{array}{l}\text { A score of } 1 \text { is assigned when the infant orients towards the examiner's face and voice for over } 30 \text { seconds, while head and trunk } \\
\text { are supported by the examiner. The infant is able to follow with eyes and head horizontally over an arc of } 180^{\circ} \text {. By contrast, a } \\
\text { score of } 5 \text { is given when the infant never succeeds in orienting. }\end{array}$ \\
\hline 5 & Morol Startle Reaction & $\begin{array}{l}\text { Typically thought of solely in reflexive terms it is often unrecognized that when the startle reaction is overactive, the infant cannot } \\
\text { achieve a good head control. Consequently, this item is scored on the basis of the infant's capacity to control the influence of } \\
\text { Moro/startle and then lift his head to follow a stimulus in a vertical position (sitting position helped by the examiner). A score of } 1 \text { is }\end{array}$ \\
\hline
\end{tabular}




\begin{tabular}{|c|c|c|}
\hline & & $\begin{array}{l}\text { given when the infant is able to gain head control and follow an object for more than } 30 \text { seconds. Moro/startle reaction will be } \\
\text { evident only infrequently in the sitting position, but does not interfere with performance. By contrast, a score of } 5 \text { is given when this } \\
\text { performance is never achieved. Moro/startle reactions are always evident and stereotyped. }\end{array}$ \\
\hline 6 & $\begin{array}{l}\text { Asymmetric Tonic Neck Reflex } \\
\qquad(\text { ATNR) }\end{array}$ & $\begin{array}{l}\text { This item is scored on the basis of the infant's capacity to align and realign his head in a supine position in order to follow a } \\
\text { stimulus. A score of } 1 \text { is given when the infant follows over a horizontal arc of not less than } 180^{\circ} \text {. The ATNR is evident only } \\
\text { intermittently but does not interfere with performance. By contrast, a score of } 5 \text { is assigned when the performance is never } \\
\text { achieved. The ATNR is always evident and stereotyped and the infant never realigns his head to follow a stimulus. }\end{array}$ \\
\hline 7 & $\begin{array}{l}\text { Head Righting Reactions in a Prone } \\
\text { Position }\end{array}$ & $\begin{array}{l}\text { This item is scored according to the duration the infant is able to keep his head raised in order to follow an object or a face. A } \\
\text { score of } 1 \text { is given when the time for following is greater than } 30 \text { seconds. By contrast, a score of } 5 \text { is given when the performance } \\
\text { is never accomplished. }\end{array}$ \\
\hline 8 & $\begin{array}{l}\text { Head-Righting Reactions During } \\
\text { 'Pull-to-Sit' Maneuver }\end{array}$ & $\begin{array}{l}\text { The score for this item is based on the infant's ability to control his head during the pull-to-sit. A score of } 1 \text { is given when the head } \\
\text { is held in a straight line with the trunk. By contrast, a score of } 5 \text { is given when the head flops completely. }\end{array}$ \\
\hline 9 & $\begin{array}{l}\text { Body-Righting Reactions in Prone } \\
\text { Position }\end{array}$ & $\begin{array}{l}\text { This item addresses the infant's ability to extend his head and the upper part of his trunk and bear weight on his forearms in order } \\
\text { to follow a stimulus; this ensures the possibility of shifting weight to one side and thus freeing one hand for manipulation. The } \\
\text { score is based on the length of time the infant extends his head and the upper part of his trunk and supports his weight. A score of } \\
1 \text { is given when the duration is greater than } 30 \text { seconds. By contrast, a score of } 5 \text { is given when the performance is never } \\
\text { achieved. }\end{array}$ \\
\hline 10 & Grasp Reflex & $\begin{array}{l}\text { This item is scored on the basis of the infant's capacity to bring his hands to the midline in a supine position; scores from } 1 \text { to } 4 \\
\text { depend on the number of facilitations needed to accomplish this performance (e.g., gentle caressing of the dorsal surface may } \\
\text { facilitate hand opening when the hands are clenched). A score of I is given when the infant is able to open his hands and bring } \\
\text { them to the midline with smooth, well-directed movements, isolated finger movements, without facilitation. The grasp reflex is } \\
\text { evident only intermittently but does not interfere with the performance. By contrast, a score of } 5 \text { is given when the performance is } \\
\text { never achieved; the grasp reflex is always evident and stereotyped or the movement of the upper limbs is so poor that no } \\
\text { functional activity can be performed. }\end{array}$ \\
\hline 11 & Positive Supporting Reaction & $\begin{array}{l}\text { This item is scored on the basis of the infant's capacity to interrupt the typical pattern of this reaction (i.e., simultaneous extension } \\
\text { of hip and knee associated with plantiflexion of the ankle joint) and its reversal (simultaneous flexion of hip and knee associated }\end{array}$ \\
\hline
\end{tabular}




\begin{tabular}{|l|l|l|}
\hline & $\begin{array}{l}\text { with dorsiflexion of the ankle joint) showing isolated hip, knee, ankle movements. A score of } 1 \text { is given when the infant is actively } \\
\text { kicking and shows isolated hip, knee, and ankle movements throughout the examination. Simultaneous hip, knee, and ankle } \\
\text { extension and flexion are evident only intermittently but they do not interfere with isolated movements. By contrast, a score of } 5 \text { is } \\
\text { given if active kicking is absent or occurs only and exclusively as part of a total extension or total flexion pattern, while isolated } \\
\text { movements are never observed. }\end{array}$ \\
\hline
\end{tabular}

* Adopted from: Bottos M, Dalla Barba B, D'Este A, Tronick EZ. The Neurobehavioral Assessment Scale as an instrument for early long-term prognosis and intervention in major disability in high-risk infants. J Pediatr Psychol. 1996;21: 755-769, and reprinted with permission. 
Table S-4. NNT with Repeated Ephedrine.*

\begin{tabular}{lccc}
\hline \multicolumn{1}{c}{ NNT } & Crystalloid $(\mathbf{n}=\mathbf{4 6 9})$ & Colloid $(\mathbf{n}=\mathbf{4 7 0})$ & p Value \\
\hline Epidural & & & \\
Pre-loading & $19(4.1)$ & $10(2.1)$ & 0.088 \\
Co-loading & $35(7.5)$ & $28(6.0)$ & 0.36 \\
Post-loading & $41(8.7)$ & $34(7.2)$ & 0.39 \\
Spinal & & & \\
Pre-loading & $25(5.3)$ & $8(1.7)$ & 0.002 \\
Co-loading & $46(9.8)$ & $30(6.4)$ & 0.054 \\
Post-loading & $53(11.3)$ & $42(8.9)$ & 0.23 \\
\hline
\end{tabular}

* Data are presented as the number (\%). NNT: number-needed-to-treat 
Table S-5. Obstetric and Anesthetic Data.*

\begin{tabular}{|c|c|c|c|}
\hline Variable & Crystalloid & Colloid & p Value \\
\hline \multicolumn{4}{|l|}{ Duration of fluid infusion, min } \\
\hline Pre-epidural & $8(7-11)$ & $9(6-12)$ & 0.67 \\
\hline Co-epidural & $8(6-11)$ & $8(7-12)$ & 0.18 \\
\hline Post-epidural & $9(7-13)$ & $10(7-13)$ & 0.42 \\
\hline Pre-spinal & $7(5-11)$ & $8(7-11)$ & 0.23 \\
\hline Co-spinal & $9(7-12)$ & $9(7-12)$ & 0.81 \\
\hline Post-spinal & $7(5-13)$ & $8(6-11)$ & 0.72 \\
\hline \multicolumn{4}{|c|}{ Induction of neuraxial anaesthesia, min } \\
\hline Pre-epidural & $10(8-13)$ & $9(8-14)$ & 0.88 \\
\hline Co-epidural & $9(7-11)$ & $9(8-12)$ & 0.49 \\
\hline Post-epidural & $11(8-13)$ & $10(7-13)$ & 0.78 \\
\hline Pre-spinal & $9(6-12)$ & $11(8-13)$ & 0.31 \\
\hline Co-spinal & $10(9-14)$ & $10(7-12)$ & 0.70 \\
\hline Post-spinal & $9(7-13)$ & $10(7-13)$ & 0.42 \\
\hline \multicolumn{4}{|c|}{ Anaesthetic induction to skin incision, min } \\
\hline Pre-epidural & $16(14-21)$ & $18(13-22)$ & 0.55 \\
\hline Co-epidural & $19(16-25)$ & $17(14-22)$ & 0.40 \\
\hline Post-epidural & $18(15-23)$ & $17(15-24)$ & 0.38 \\
\hline Pre-spinal & $9(8-12)$ & $11(7-12)$ & 0.84 \\
\hline Co-spinal & $10(7-12)$ & $10(8-13)$ & 0.17 \\
\hline Post-spinal & $8(7-13)$ & $9(7-12)$ & 0.74 \\
\hline \multicolumn{4}{|l|}{ Uterine incision to delivery, min } \\
\hline Pre-epidural & $3(2-4)$ & $3(2-5)$ & 0.54 \\
\hline Co-epidural & $3(2-4)$ & $3(2-4)$ & 0.42 \\
\hline Post-epidural & $2(2-4)$ & $3(2-5)$ & 0.84 \\
\hline Pre-spinal & $3(2-5)$ & $3(2-5)$ & 0.69 \\
\hline Co-spinal & $3(3-5)$ & $3(2-4)$ & 0.78 \\
\hline Post-spinal & $3(2-4)$ & $2(2-5)$ & 0.84 \\
\hline \multicolumn{4}{|l|}{ Duration of anaesthesia, min } \\
\hline Pre-epidural & $145(123-169)$ & $152(136-177)$ & 0.62 \\
\hline Co-epidural & $150(131-182)$ & $142(130-180)$ & 0.49 \\
\hline Post-epidural & $138(120-156)$ & $144(127-168)$ & 0.89 \\
\hline Pre-spinal & $121(113-142)$ & $132(127-159)$ & 0.69 \\
\hline Co-spinal & $130(128-148)$ & $125(110-146)$ & 0.36 \\
\hline Post-spinal & $128(116-154)$ & $120(114-137)$ & 0.41 \\
\hline \multicolumn{4}{|l|}{ Duration of surgery, min } \\
\hline Pre-epidural & $48(40-55)$ & $50(45-61)$ & 0.68 \\
\hline Co-epidural & $44(38-51)$ & $46(40-60)$ & 0.31 \\
\hline Post-epidural & $52(42-68)$ & $55(41-67)$ & 0.69 \\
\hline Pre-spinal & $46(42-54)$ & $53(40-62)$ & 0.55 \\
\hline Co-spinal & $55(46-60)$ & $47(39-58)$ & 0.84 \\
\hline
\end{tabular}




\begin{tabular}{lccc}
\hline $\begin{array}{c}\text { Post-spinal } \\
\text { Highest sensory block level }\end{array}$ & $46(40-58)$ & $50(44-67)$ & 0.42 \\
Pre-epidural & $\mathrm{T} 7(\mathrm{~T} 6-\mathrm{T} 8)$ & $\mathrm{T} 7(\mathrm{~T} 7-\mathrm{T} 8)$ & 0.91 \\
Co-epidural & $\mathrm{T} 6(\mathrm{~T} 6-\mathrm{T} 8)$ & $\mathrm{T} 7(\mathrm{~T} 6-\mathrm{T} 7)$ & 0.88 \\
Post-epidural & $\mathrm{T} 7(\mathrm{~T} 6-\mathrm{T} 8)$ & $\mathrm{T} 6(\mathrm{~T} 6-\mathrm{T} 8)$ & 0.89 \\
Pre-spinal & $\mathrm{T} 8(\mathrm{~T} 6-\mathrm{T} 9)$ & $\mathrm{T} 7(\mathrm{~T} 7-\mathrm{T} 8)$ & 0.94 \\
Co-spinal & $\mathrm{T} 7(\mathrm{~T} 6-\mathrm{T} 8)$ & $\mathrm{T} 7(\mathrm{~T} 7-\mathrm{T} 8)$ & 0.99 \\
Post-spinal & $\mathrm{T} 7(\mathrm{~T} 6-\mathrm{T} 7)$ & $\mathrm{T} 8(\mathrm{~T} 6-\mathrm{T} 8)$ & 0.87 \\
Estimated blood loss, ml & & & \\
Pre-epidural & $340(310-380)$ & $350(330-400)$ & 0.48 \\
Co-epidural & $320(280-410)$ & $300(270-370)$ & 0.57 \\
Post-epidural & $360(330-400)$ & $320(300-380)$ & 0.54 \\
Pre-spinal & $350(330-420)$ & $340(310-430)$ & 0.95 \\
Co-spinal & $330(300-410)$ & $300(290-350)$ & 0.17 \\
Post-spinal & $360(320-430)$ & $370(340-450)$ & 0.35 \\
Additional fluid volume, ml & & & \\
Pre-epidural & $525(481-666)$ & $550(512-693)$ & 0.64 \\
Co-epidural & $538(504-635)$ & $517(476-640)$ & 0.37 \\
Post-epidural & $574(522-703)$ & $556(508-686)$ & 0.47 \\
Pre-spinal & $543(516-687)$ & $589(530-721)$ & 0.59 \\
Co-spinal & $572(542-710)$ & $554(470-673)$ & 0.22 \\
Post-spinal & $521(490-687)$ & $561(531-692)$ & 0.79 \\
\hline
\end{tabular}

* Data denotes median and interquartile range (IQR) analyzed with Mann-Whitney U test. 
Table S-6. Infant Outcomes.

\begin{tabular}{|c|c|c|c|}
\hline Outcome & $\begin{array}{l}\text { Crystalloid } \\
(n=469)\end{array}$ & $\begin{array}{l}\text { Colloid } \\
(n=470)\end{array}$ & p Value \\
\hline \multicolumn{4}{|l|}{ Pre-epidural } \\
\hline Weight, $g$ & $3310 \pm 450$ & $3230 \pm 380$ & 0.83 \\
\hline 1-min Apgar < 7, n (\%) & $5(1.1)$ & $6(1.3)$ & 0.64 \\
\hline 5-min Apgar < 7, n (\%) & 0 & 0 & - \\
\hline Low umbilical cord $\mathrm{pH}$ (artery < 7.20), n (\%) & $12(2.6)$ & $9(1.9)$ & 0.50 \\
\hline NBAS scorings (median [IQR]) & $18(12-27)$ & $15(12-30)$ & 0.69 \\
\hline \multicolumn{4}{|l|}{ Co-epidural } \\
\hline Weight,g & $3420 \pm 290$ & $3270 \pm 360$ & 0.60 \\
\hline 1-min Apgar < 7, n (\%) & $7(1.5)$ & $5(1.1)$ & 0.56 \\
\hline 5-min Apgar < 7, n (\%) & 0 & 0 & - \\
\hline Low umbilical cord pH (artery < 7.20), n (\%) & $13(2.8)$ & $11(2.3)$ & 0.67 \\
\hline NBAS scorings (median [IQR]) & $17(13-31)$ & $16(11-28)$ & 0.55 \\
\hline \multicolumn{4}{|l|}{ Post-epidural } \\
\hline Weight, g & $3300 \pm 315$ & $3410 \pm 280$ & 0.56 \\
\hline 1-min Apgar < 7, n (\%) & $9(1.9)$ & $8(1.7)$ & 0.80 \\
\hline 5-min Apgar < 7, n (\%) & $1(0.2)$ & 0 & 0.32 \\
\hline Low umbilical cord pH (artery < 7.20), n (\%) & $15(3.2)$ & $17(3.6)$ & 0.72 \\
\hline NBAS scorings (median [IQR]) & $21(15-36)$ & $19(14-34)$ & 0.70 \\
\hline \multicolumn{4}{|l|}{ Pre-spinal } \\
\hline Weight, g & $3150 \pm 340$ & $3210 \pm 270$ & 0.78 \\
\hline 1-min Apgar < 7, n (\%) & $3(0.6)$ & $3(0.6)$ & 0.99 \\
\hline 5-min Apgar < 7, n (\%) & 0 & 0 & - \\
\hline Low umbilical cord pH (artery < 7.20), n (\%) & $8(1.7)$ & $5(1.1)$ & 0.40 \\
\hline NBAS scorings (median [IQR]) & $13(11-21)$ & $14(11-23)$ & 0.58 \\
\hline \multicolumn{4}{|l|}{ Co-spinal } \\
\hline Weight, g & $3290 \pm 310$ & $3310 \pm 270$ & 0.69 \\
\hline 1-min Apgar < 7, n (\%) & $6(1.3)$ & $4(0.8)$ & 0.52 \\
\hline 5-min Apgar < 7, n (\%) & 0 & $1(0.2)$ & 0.31 \\
\hline Low umbilical cord pH (artery < 7.20), n (\%) & $11(2.3)$ & $9(1.9)$ & 0.65 \\
\hline NBAS scorings (median [IQR]) & $17(13-25)$ & $18(12-29)$ & 0.70 \\
\hline \multicolumn{4}{|l|}{ Post-spinal } \\
\hline Weight, g & $3320 \pm 280$ & $3200 \pm 300$ & 0.64 \\
\hline 1-min Apgar < 7, n (\%) & $8(1.7)$ & $7(1.5)$ & 0.79 \\
\hline 5-min Apgar < 7, n (\%) & $1(0.2)$ & 0 & 0.32 \\
\hline Low umbilical cord pH (artery < 7.20), n (\%) & 15 (3.2) & $12(2.6)$ & 0.55 \\
\hline NBAS scorings (median [IQR]) & $17(15-30)$ & $19(16-36)$ & 0.31 \\
\hline
\end{tabular}

NBAS: neurobehavioral assessment scale; IQR: interquartile range 
Table S-7. Maternal Adverse Events during Intervention Period.

\begin{tabular}{|c|c|c|c|c|c|c|c|c|c|c|c|c|}
\hline \multirow[b]{3}{*}{ Adverse Event } & \multicolumn{6}{|c|}{ Crystalloid } & \multicolumn{6}{|c|}{ Colloid } \\
\hline & \multicolumn{3}{|c|}{ Epidural } & \multicolumn{3}{|c|}{ Spinal } & \multicolumn{3}{|c|}{ Epidural } & \multicolumn{3}{|c|}{ Spinal } \\
\hline & Pre & Co & Post & Pre & Co & Post & Pre & Co & Post & Pre & Co & Post \\
\hline Nausea/Vomiting & 3 & 3 & 5 & 2 & 6 & 8 & 2 & 5 & 7 & 6 & 4 & 6 \\
\hline Fatigue & 2 & 1 & 1 & 2 & 3 & 1 & 2 & 1 & 1 & 0 & 2 & 1 \\
\hline Haemorrhage & 0 & 0 & 1 & 2 & 0 & 0 & 0 & 1 & 0 & 0 & 1 & 1 \\
\hline Pruritus & 2 & 1 & 1 & 1 & 0 & 1 & 1 & 2 & 1 & 2 & 2 & 1 \\
\hline Headache & 0 & 1 & 0 & 1 & 1 & 0 & 1 & 0 & 0 & 0 & 0 & 2 \\
\hline Somnolence & 0 & 0 & 0 & 0 & 1 & 0 & 0 & 1 & 0 & 0 & 0 & 1 \\
\hline Hallucination & 1 & 0 & 0 & 0 & 0 & 0 & 0 & 0 & 0 & 0 & 0 & 0 \\
\hline Sweating & 2 & 0 & 0 & 1 & 1 & 0 & 0 & 0 & 0 & 0 & 2 & 0 \\
\hline Shivering & 1 & 1 & 3 & 1 & 2 & 3 & 1 & 2 & 2 & 3 & 4 & 1 \\
\hline Hypothermia & 0 & 1 & 1 & 0 & 2 & 1 & 1 & 1 & 0 & 0 & 0 & 1 \\
\hline Pulmonary aedema & 0 & 0 & 0 & 0 & 0 & 0 & 0 & 0 & 0 & 0 & 1 & 0 \\
\hline Total & 9 & 7 & 11 & 9 & 16 & 13 & 7 & 11 & 10 & 9 & 14 & 13 \\
\hline
\end{tabular}


Figure S-1. Flow of Multi-Stage Randomization.

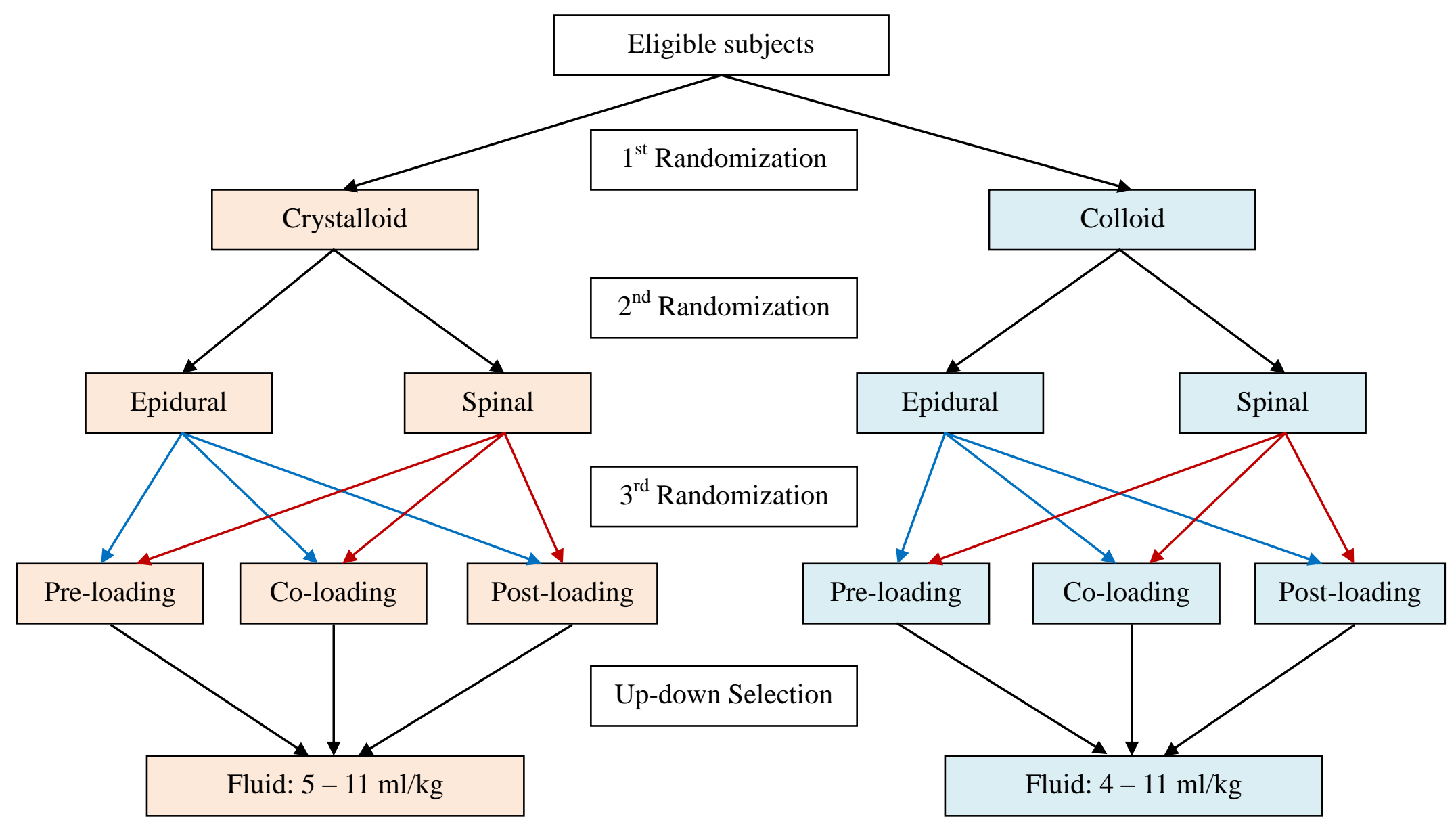

$12 / 13$ 
Figure S-2. Odds Ratios for Hypotension in Stratified Fluid Volumes.

Crystalloid and colloid all have a higher tendency of developing hypotension at the volume of less than $7 \mathrm{ml} / \mathrm{kg}$ compared with those received relatively larger dose of fluids.

A

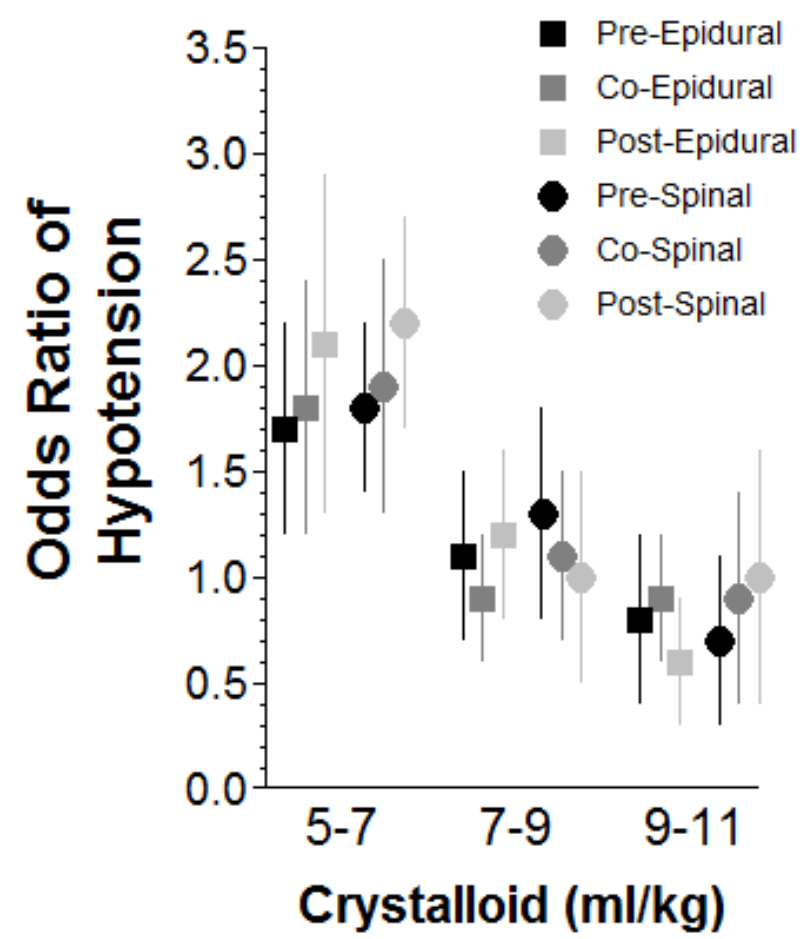

B

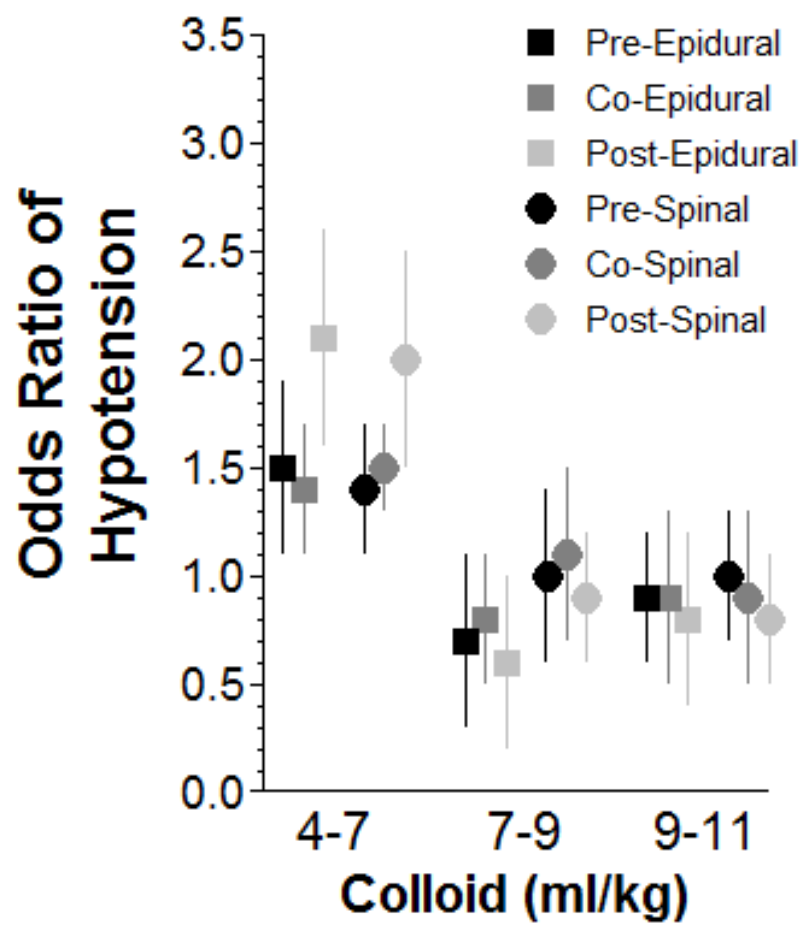

